\title{
QUEEN'S
UNIVERSITY
BELFAST
}

\section{Compatible or conflicting? Peer norms and minority and majority adolescents' acculturation patterns}

Hillekens, J., Baysu, G., \& Phalet, K. (2019). Compatible or conflicting? Peer norms and minority and majority adolescents' acculturation patterns. Journal of Applied Developmental Psychology, 65, [101074]. https://doi.org/10.1016/j.appdev.2019.101074

\section{Published in:}

Journal of Applied Developmental Psychology

\section{Document Version:}

Peer reviewed version

Queen's University Belfast - Research Portal:

Link to publication record in Queen's University Belfast Research Portal

\section{Publisher rights}

Copyright 2019 Elsevier Inc.

This manuscript is distributed under a Creative Commons Attribution-NonCommercial-NoDerivs License

(https://creativecommons.org/licenses/by-nc-nd/4.0/), which permits distribution and reproduction for non-commercial purposes, provided the author and source are cited.

\section{General rights}

Copyright for the publications made accessible via the Queen's University Belfast Research Portal is retained by the author(s) and / or other copyright owners and it is a condition of accessing these publications that users recognise and abide by the legal requirements associated with these rights.

Take down policy

The Research Portal is Queen's institutional repository that provides access to Queen's research output. Every effort has been made to ensure that content in the Research Portal does not infringe any person's rights, or applicable UK laws. If you discover content in the Research Portal that you believe breaches copyright or violates any law, please contact openaccess@qub.ac.uk. 


\title{
Compatible or conflicting?
}

Peer norms and minority and majority adolescents' acculturation patterns

\author{
Jessie Hillekens ${ }^{1}$, Jessie.Hillekens@kuleuven.be, \\ Gülseli Baysu², G.Baysu@qub.ac.uk, \\ Karen Phalet ${ }^{1}, \underline{\text { Karen.Phalet@kuleuven.be }}$
}

${ }^{1}$ Center for Social and Cultural Psychology, University of Leuven, Tiensestraat 102, 3000

Leuven, Belgium

${ }^{2}$ School of Psychology, Queen's University Belfast, 2017 University Road, BT7 1NN

Belfast, Northern Ireland, United Kingdom

Corresponding author: Jessie Hillekens, Jessie.Hillekens@ @uleuven.be, 003216326470 ,

Center for Social and Cultural Psychology, University of Leuven, Tiensestraat 102, box 3727, 3000 Leuven, Belgium

This work was supported by grants from the Research Foundation Flanders (Fonds Wetenschappelijk Onderzoek - grant number FWO G.0747.13) and the University of Leuven Research Council (Interdisciplinaire Onderzoeksprogramma - grant number IDO 10.005). 


\title{
Compatible or conflicting?
}

Peer norms and minority and majority adolescents' acculturation patterns

\begin{abstract}
Minority and majority acculturation orientations (i.e., their preferences for minorities) show consistent intergroup asymmetries: Minority adolescents see heritage and mainstream culture orientations as compatible (i.e., positively correlated), whereas majority adolescents see them as conflicting (i.e., negatively correlated). It remains unclear (a) how minority and majority adolescents' compatible versus conflicting acculturation patterns evolve over time; and (b) how peer acculturation norms in school affect evolving individual acculturation patterns. Multi-level autoregressive cross-lagged panel models with Turkish-/Moroccan-minority $(N=$ $\left.1147, M_{\mathrm{age}}=15.60\right)$ and Belgian-majority $\left(N=1716 ; M_{\mathrm{age}}=15.08\right)$ adolescents in the same schools $(N=69)$ revealed that mainstream and heritage culture orientations were partially compatible over time for minorities, yet conflicting for majority adolescents. Moreover, peer acculturation norms predicted individual acculturation orientations longitudinally, in line with existing asymmetric acculturation patterns across minority and majority adolescents.
\end{abstract}

\section{Highlights}

- Minorities' mainstream and heritage culture orientations are compatible over time.

- Majorities' mainstream and heritage culture orientations are conflicting over time.

- Peer norms reinforce existing asymmetric acculturation patterns over time.

- Compatible peer acculturation patterns for minorities depend on minority presence.

Keywords

Acculturation; Minority, Majority, Adolescence; Peer norms; Compatibility, Conflict; Intergroup relations; Longitudinal, Development; 


\section{Introduction}

Due to migration and globalization, adolescents' worlds are becoming increasingly culturally diverse. As they venture out in wider social circles beyond their parental family and community (Vollebergh, Iedema, \& Raaijmakers, 2001), they come into contact with peers from different cultural backgrounds. In daily peer interactions, both immigrant minority and majority adolescents learn about cultural differences and intercultural relations (Miklikowska, 2017). In light of increasing peer influence during adolescence (Brechwald \& Prinstein, 2011), we focus on today's culturally diverse schools as critical acculturation contexts for adolescents. We conceive of acculturation processes as part of adolescent development in the peer context (Schachner, Van de Vijver, \& Noack, 2017; Titzmann \& Lee, 2018). To distinguish minority and majority group perspectives, we combine Bronfenbrenner's (1979) ecological-systems theory of adolescent development with an intergroup-relations approach of acculturation (Brown \& Zagefka, 2011). Specifically, our study aims to establish distinct acculturation patterns for minority and majority adolescents over time, and to elucidate how these patterns are informed by peer acculturation norms in culturally-diverse schools.

The process of acculturation refers to changes in the cultural orientations of both minority and majority adolescents as a consequence of sustained intergroup contact (Berry, Phinney, Sam, \& Vedder, 2006). From an intergroup-relations perspective on acculturation (Brown \& Zagefka, 2011), minority and majority adolescents learn about the cultural orientations of their peers through repeated intergroup interactions while they are developing their own orientations. According to a well-established bi-dimensional acculturation framework, cultural orientations refer to both the mainstream culture of the receiving society and the heritage culture of the origin societies (Berry, 1997; Ryder, Alden \& Paulus, 2000). Thus, minority and majority adolescents may prefer that minorities adopt the mainstream culture ('adoption'), maintain the heritage culture ('maintenance'), or combine both cultures 
('integration'; Berry, 1997; Brown \& Zagefka, 2011; Ryder et al., 2000). Minority

adolescents most often prefer integration, combining mainstream and heritage cultures

(Berry, et al., 2006), and they typically see both cultures as compatible (e.g., Nesdale \& Mak, 2000 for empirical evidence; see Mesquita, De Leersnyder, \& Jasini, 2017 for a review). We do not know, however, whether both acculturation orientations in minority youth are also compatible over time. In line with compatibility, we ask whether heritage culture maintenance and mainstream culture adoption are mutually reinforcing in minority adolescents over time.

From an intergroup relations perspective on acculturation (Brown \& Zagefka, 2011), immigrant minorities negotiate their acculturation orientations in relation to the majority group. Majority groups may expect that minorities adopt the mainstream culture, or maintain the heritage culture, or that they combine the cultures (Bourhis, Moïse, Perreault, \& Sénécal, 1997). Majority populations in European migration contexts most often prioritize that minorities adopt the mainstream culture, which they typically see as conflicting with minorities' heritage culture (Brown \& Zagefka, 2011). Although majority acculturation orientations have mainly been studied in adults, there is some evidence of a conflicting acculturation pattern in majority adolescents as well (Van Acker \& Vanbeselaere, 2012). From a majority perspective then, in order to fully adopt the mainstream culture, minorities would have to relinquish the heritage culture of their countries of origin. If majorities see mainstream and heritage cultures as conflicting and minorities see both cultures as compatible, the resulting mismatch between minority and majority group perspectives on acculturation threatens positive intergroup relations (Brown \& Zagefka, 2011). Such intergroup threat jeopardizes the psychological viability and adaptive value of integration for immigrant minorities (see Phalet \& Baysu, forthcoming, for a review). Still, majority adolescents remain understudied in acculturation research. Our study asks whether both 
acculturation orientations are also conflicting over time in the eyes of majority adolescents, so that their preferences for minorities to adopt the mainstream culture or to maintain the heritage culture are mutually attenuating over time.

Extending an emergent literature on bicultural identity integration and dual identity conflict versus compatibility (Benet-Martínez, Leu, Lee, \& Morris, 2002; Fleischmann \& Phalet, 2016), we narrowly define compatibility as positive longitudinal associations between both cultural orientations, so that adopting the mainstream culture and maintaining the heritage culture are mutually reinforcing over time. A compatible acculturation pattern implies that being securely rooted in the heritage culture would enable minority adolescents to engage more fully in future mainstream culture contact and learning; and that positive contact experiences with the mainstream culture would further affirm the value of their cultural heritage. This pattern ideally corresponds to the minority experience of acculturation. Conversely, we define conflict as negative longitudinal associations between mainstream and heritage cultural orientations, so that adoption of the mainstream culture and maintenance of the heritage culture are mutually attenuating over time. A conflicting acculturation pattern implies that heritage culture maintenance would hinder or restrict minorities in their future engagement in mainstream culture contact and learning; and that the adoption of the mainstream culture would in turn keep them from maintaining their cultural heritage. This pattern reflects the typical majority perspective on acculturation. Note that the absence of conflict (i.e., dissociation between both acculturation orientations) would neither support nor contradict compatibility (Fleischmann \& Phalet, 2016). Summing up, our first research aim is to establish compatible versus conflicting acculturation patterns over time for minority and majority adolescents respectively.

Compatible or conflicting acculturation patterns not only differ between minority and majority groups, but the extent of conflict or compatibility between heritage and mainstream 
cultural orientations also varies across acculturation contexts (Fleischmann \& Phalet, 2016). More generally, from an ecological-systems theory approach (Bronfenbrenner, 1979), adolescents' development is embedded in their immediate environment, which consists of different subsystems of relationships, such as peer relations in school, which are in turn embedded in the wider societal environment. We focus on peer relations here because adolescents' opinions, attitudes, and orientations in many life domains are influenced by peer norms (Brechwald \& Prinstein, 2011). Specifically, we conceive of adolescents' acculturation orientations as negotiated cultural commitments in ongoing social interactions within culturally diverse schools (Schachner, Juang, Moffitt, \& Van de Vijver, 2018; Schachner et al., 2017). Within the school context, we zoom in on peer groups as a critical yet understudied acculturation context for adolescents. Since the ecological-systems theory of adolescent development does not articulate a distinct minority perspective (Syed, Santos, Yoo, \& Juang, 2018), we add on an intergroup-relations approach of acculturation (Brown \& Zagefka, 2011) to derive distinct minority and majority group perspectives within culturally diverse schools. More precisely, we ask how peer acculturation norms contribute to distinct acculturation patterns of compatibility versus conflict over time for minority and majority adolescents respectively. There is cross-sectional evidence associating peer norms of acculturation with individual acculturation orientations for minority adolescents (Celeste, Meeussen, Verschueren, \& Phalet, 2016; Titzmann \& Jugert, 2015). Extending these findings longitudinally, we predict adolescents' own acculturation orientations from the acculturation norms of their peers in the same schools while taking into account their own earlier acculturation orientations. Thus, our second research aim is to investigate how peer acculturation norms contribute to distinct acculturation patterns for minority and majority adolescents over time. 
To address our research aims, we draw on large-scale longitudinal surveys of Turkish and Moroccan minority and Belgian majority adolescents in the same schools (CILSBelgium; Phalet, Meuleman, Hillekens, \& Sekaran, 2018). As a stringent test of compatibility versus conflict in adolescents' evolving acculturation patterns, we estimated autoregressive cross-lagged panel models with two waves (one year apart). In addition, we aggregated actual peer norms at the school-level as contextual predictors of adolescents' individual acculturation orientations over time in multi-level models. We derive theoretical expectations from a combined ecological-systems and intergroup-relations approach of peer acculturation norms and evolving acculturation patterns in minority and majority adolescents.

\section{Minority and majority acculturation orientations: compatible or conflicting over time?}

Adolescence is a crucial period in the development of acculturation orientations. As minority and majority youth engage in expanding social worlds, they face the challenge of making sense of new intercultural experiences (Miklikowska, 2017; Rutland \& Killen, 2015). As a consequence of new social experiences and of their social-cognitive and moral development, adolescents' intercultural understanding changes (Rutland \& Killen, 2015). Thus, minority and majority adolescents alike become increasingly aware of the societal status of their respective groups (Rubin, Bukowski, Parker, \& Bowker, 2008); they develop stereotypes of other groups (for a review, see Killen, Mulvey, \& Hitti, 2013); and peer influence on their attitudes towards other cultural groups peaks in adolescence, wearing off in early adulthood (Wölfer, Schmid, Hewstone, \& Van Zalk, 2016).

Minority adolescents, more specifically, are increasingly aware of their minority status and explore different cultural values, norms, and practices as they are negotiating culturally diverse social worlds (Miklikowska, 2017). Due to their minority position in the wider society, they have to balance the heritage culture of their family and co-ethnic peers with the mainstream culture that is taught in school. Along those lines, there is evidence that 
Turkish minority youth are more oriented towards the mainstream culture in school than at home, while heritage cultural orientations vary with the presence of minority peers in school (Arends-Tòth \& Van de Vijver, 2003; Phalet \& Andriessen, 2004). Accordingly, mainstream cultural orientations are generally adaptive for minority youth in the school context; and heritage cultural orientations can additionally protect well-being in school (Schachner, Van de Vijver, \& Noack, 2018). Together, these findings suggest that mainstream and heritage cultural orientations can be compatible for minority youth in school. Despite extensive correlational evidence of compatibility in minorities' general acculturation patterns within time (Brown \& Zagefka, 2011; Mesquita et al., 2017; Nesdale \& Mak, 2000), there is no direct evidence of compatibility in the school context, nor is there any longitudinal evidence of compatibility over time.

In indirect support of compatibility over time for minority youth, there is longitudinal evidence that heritage and mainstream cultural orientations co-evolve over time. Thus, Brown (et al., 2013) found among minority children in British schools that both mainstream and heritage cultural orientations increased over time; and that older children more often preferred integration, or the combination of heritage and mainstream cultures, than younger children. Similarly, Schwartz (et al., 2015) identified either high and stable, or increasing mainstream culture and heritage culture orientations in Hispanic minority youth in the US. Additional indirect support for compatibility over time comes from longitudinal associations between ethnic and national cultural identifications in minority adolescents. In the U.S., minority youth with stronger national identities showed stronger increases in ethnic identity over time (Fuller-Rowell, Ong, \& Phinney, 2013). Similarly, minority adolescents in Chili with increasing ethnic identification over time also increasingly adopted the mainstream culture over time (González et al., 2017). These findings of positive longitudinal associations between ethnic and national cultural identities suggest compatibility over time. While cultural 
identifications overlap with acculturation orientations (Güngör, Bornstein, \& Phalet, 2012), we do not know whether compatible self-identities over time generalize to cultural preferences and practices in the European school context.

Our study extends first indirect evidence of compatibility within and over time by directly assessing the longitudinal associations between heritage and mainstream cultural orientations. In the Belgian school context we focus on Turkish and Moroccan immigrant minorities, because these groups face widespread public prejudice (Voas \& Fleischmann, 2012) and persistent educational disadvantage (Heath \& Brinbaum, 2014). Compared to majority youth, Turkish and Moroccan minority youth are underachieving and overrepresented in vocational (versus academic) tracks of secondary school with long-term consequences for their future life chances (Baysu, Alanya, \& De Valk, 2018). Within Turkish and Moroccan immigrant families and communities, generally strong and stable orientations towards the heritage culture are effectively transmitted as a valued source of social support and cultural continuity (Phalet, Fleischmann \& Hillekens, 2018). At the same time, Turkish and Moroccan minority adolescents are also strongly oriented towards the mainstream culture in the school context (cf. supra; Phalet \& Andriessen, 2004; Schachner, Van de Vijver, et al., 2018). As a stringent test of the compatibility hypothesis, this study directly tests whether minority adolescents' heritage and mainstream cultural orientations are mutually reinforcing in line with compatibility over time, over and above compatibility within time (i.e., controlling for their association within time). Specifically, we predict that minority adolescents who value mainstream culture adoption more than others at time 1 will also value heritage culture maintenance more than others at time 2 (controlling for their own maintenance at time 1); and minorities who value maintenance more than others at time 1 will also value adoption more than others at time 2 (controlling for their own adoption at time $1)$. 
We tested the same longitudinal associations between both acculturation orientations also for majority adolescents. From an intergroup-relations approach of acculturation, we expect that distinct majority (versus minority) group perspectives will be reflected in asymmetric acculturation patterns for majority (versus minority) youth. As majority adolescents are engaging in intergroup contact with their minority peers in school, they become more aware of their majority group status in intergroup relations (Rubin et al., 2008; Rutland \& Killen, 2015); and they form stereotypes of (minority) outgroups (Killen, Mulvey et al., 2013) which accentuate cultural difference. Although we know of no developmental research about longitudinal acculturation patterns in majority adolescents, these changes in intergroup attitudes and stereotypes in adolescence may underlie a hypothetical conflicting pattern for majority adolescents.

In the absence of longitudinal evidence on the acculturation orientations of majority adolescents, there is converging cross-sectional evidence in line with a prevailing conflicting pattern of majority acculturation orientations in the European migration context. For instance, Arends-Tòth and Van de Vijver (2003) found that majority-Dutch adults preferred that Turkish-Dutch minorities would fully adopt the Dutch mainstream culture without maintaining the Turkish heritage culture. Similarly, majority-Dutch adults evaluated minority persons who prioritized only the mainstream culture more positively than those who combined both cultures (Van Oudenhoven, Prins, \& Buunk, 1998). Finally, Van Acker and Vanbeselaere (2012) found experimental evidence of a conflicting acculturation pattern in majority-Belgian adolescents: they perceived less mainstream culture adoption by immigrant minorities when the latter were represented as maintaining the heritage culture more in a vignette experiment.

Looking beyond conflicting acculturation orientations within time, this study aims to examine whether majority adolescents' heritage and mainstream cultural orientations will 
mutually attenuate each other in line with conflict over time, over and above conflict within time (i.e., controlling for their association within time). Specifically, we predict that majority adolescents who value mainstream culture adoption more than others at time 1 will value heritage culture maintenance less than others at time 2 (controlling for their own maintenance at time 1); and majorities who value heritage culture maintenance more than others at time 1 will value adoption less than others at time 2 (controlling for their own adoption at time 1).

\section{Peer acculturation norms in culturally diverse schools}

From an ecological-systems approach of adolescent development (Bronfenbrenner, 1979), acculturation orientations develop during adolescence and this development is afforded by adolescents' social environment (Motti-Stefanidi, Berry, Chryssochoou, Sam, \& Phinney, 2012). In particular, peer relationships can shape adolescents' development through day-today interactions in the school context. From an intergroup relations approach of acculturation, today's culturally diverse schools provide both minority and majority youth with opportunities for intergroup contact among peers. More generally, peers become increasingly important during adolescence as adolescents' opinions, attitudes, and orientations are influenced by peer norms (Brechwald \& Prinstein, 2011). We focus specifically on peer norms of acculturation in culturally diverse schools, aggregating the views of all peers within the same culturally diverse school as general norms to which both minority and majority peers contribute and which jointly make up the actual normative climate at the school level (Celeste et al., 2016). While developmental research on peer norms has not usually distinguished between ethnic groups (Graham, Taylor, \& Ho, 2009), there is some evidence of influence of general peer norms for both minority and majority youth, and of the 'ethnic socialization' of minority peer norms for minority youth (Gharaei, Thijs, \& Verkuyten, 2019; Rivas-Drake, Saleem, Schaefer, Medina, \& Jagers, 2018). Since acculturation norms define the value of both heritage and mainstream cultures, we expect that adolescents' individual 
acculturation orientations will be informed by minority as well as majority peers in their school environment (Celeste et al., 2016).

First cross-sectional evidence in the school context reveals that misfit with peer acculturation norms is psychologically costly for minority adolescents. For example, Celeste (et al., 2016) showed that minority adolescents whose acculturation orientations differed from peer acculturation norms in culturally diverse Belgian classrooms, experienced more peer rejection. More precisely, peer rejection was predicted by misfit either with a general peer norm of mainstream culture adoption and/or with a minority subgroup norm of heritage culture maintenance. Similarly, Titzmann and Jugert (2015) found higher well-being for minority adolescents in German schools who were more strongly oriented towards the German mainstream culture, but only when minority peers endorsed a mainstream cultural norm. Furthermore, minority adolescents who were more oriented towards the heritage culture reported lower well-being, but only to the extent that majority peers stressed mainstream cultural norms more (Titzmann \& Jugert, 2015). In sum, minority adolescents benefit when their individual acculturation orientations fit with minority, majority, and general peer group norms.

Moreover, there is mainly cross-sectional evidence with young adult minority samples relating minority acculturation orientations to perceived acculturation norms. Thus, the acculturation orientations of Muslim minority young adults were significantly related to their perceptions of both majority and minority group norms of acculturation (Kunst \& Sam, 2013). Likewise, when minority students on a California campus perceived a stronger majority group norm of heritage culture maintenance, they were more oriented towards mainstream culture contact (Celeste, Brown, Tip, \& Matera, 2014), in line with a compatible pattern of peer influence. Finally, previous longitudinal findings of peer influence showed 
that individual cultural value orientations converge with actual peer norms over time through intergroup contact in culturally diverse student groups (Meeussen, Delvaux \& Phalet, 2014).

Extending earlier evidence, our study aims to test peer influence on evolving acculturation patterns longitudinally and across minority and majority adolescents in culturally diverse schools. To address this research aim, we examine how general peer norms of acculturation in culturally diverse schools predict individual acculturation orientations over time. We expect that general peer norms of mainstream culture adoption and heritage culture maintenance norms at time 1 will be related to more individual adoption and maintenance orientations respectively at time 2 (over and above prior individual adoption and maintenance). Additionally, in line with a hypothetical compatible acculturation pattern, we will explore whether peer norms of maintenance at time 1 (over and above individual maintenance at time 1) predict more adoption in individual minority adolescents at time 2 (over and above prior individual adoption); similarly, peer norms of adoption at time 1 may predict more individual maintenance at time 2.

Turning to majority acculturation orientations, we argue that the peer context will affect majority adolescents as well. There is some existing evidence from intergroup relations research associating majority acculturation patterns to perceived group norms (Brown \& Zagefka, 2011): Majority students on a California university campus who perceived stronger minority group norms combining heritage and mainstream cultures were more willing to engage in cross-cultural contact with minority peers (Celeste et al., 2014). While acculturation research with majority adolescents is scarce, we know that adolescents' intergroup attitudes are generally attuned to peer group norms, especially when the intergroup context makes group identities salient (McGuire, Elenbaas, Killen, \& Rutland, 2018). Furthermore, adolescents were most sensitive to peer norms, as distinct from more distant perceived norms in the wider society (Killen, Rutland, Abrams, Mulvey, \& Hitti, 2013). 
To address our second research aim, we extend the longitudinal analysis of general peer norms of acculturation in culturally diverse schools to majority adolescents' individual acculturation patterns as well. Specifically, we predict that actual peer adoption and maintenance norms at time 1 will be related to more individual adoption and maintenance orientations respectively at time 2 for majority adolescents. Additionally, and in line with a hypothetical conflicting acculturation pattern, we will explore whether general peer norms of adoption at time 1 are longitudinally associated with less individual acceptance of heritage culture maintenance at time 2 ; and conversely, whether stronger actual peer norms of heritage culture maintenance are associated with less individual preference for adoption.

How peer relations affect different acculturation patterns in minority and majority adolescents also depends on the presence of minority and majority peers in school. There is mostly indirect evidence relating school composition to the acculturation and adaptation of minority adolescents. Thus, racial minority adolescents in the U.S. felt more safe, less victimized, and more valued in schools with a larger share of minority peers (Juvonen, Kogachi, \& Graham, 2018), which can help them to express their heritage culture besides the mainstream culture (Rock, Cole, Houshyar, Lythcott, \& Prinstein, 2011). Along those lines, minority adolescents felt more accepted in classes and schools with higher shares of minority peers (Asendorpf \& Motti-Stefanidi, 2017; Juvonen et al., 2018); they also experienced more ethnic pride (Leszczensky, Flache, Stark, \& Munniksma, 2017). Also for majority adolescents, larger shares of majority peers may buffer them from feelings of threat by minority presence (Van Acker \& Vanbeselaere, 2012). While we do not have specific hypotheses about school composition, we reason that the presence of minority peers might facilitate a compatible acculturation pattern over time for minority adolescents, whereas majority peer presence might dampen conflict over time for majority adolescents. To take into account school composition, the analyses will distinguish schools with high or low 
shares of majority peers for majority adolescents, and with high or low shares of (most similar) Turkish and Moroccan minority peers for Turkish and Moroccan minority adolescents.

\section{Methods}

\section{Participants and procedure}

Adolescents participated in a large-scale longitudinal study in Flanders, Belgium (Phalet, Meuleman, et al., 2018). After obtaining ethical clearance from the principal, teachers, parents, and pupils themselves, all eligible adolescents participated in the survey during class hours in two consecutive years ${ }^{1}$. Adolescents were sampled from 69 randomly selected secondary schools, which were stratified from low ( $<10 \%$ minority students) over moderate $(10 \%-30 \%$ and $30 \%-60 \%)$ to high levels of ethnic composition (> 60\%). Within each school, participants were randomly sampled from the first (0.9\%), second (27.6\%), third (27.6\%), and fourth $(43.9 \%)$ year of lower secondary education. Adolescents in schools with less than 10 participants $(N=14)$ were excluded from analyses to ensure the reliability of the peer acculturation norms as aggregated individual orientations.

We used self-reported parentage (i.e., one or more foreign-born (grand)parents) to select a minority subsample $(N=1147)$ with a Turkish- $(N=509)$ or Moroccan-background $(N=638)$ and a majority subsample of native Belgian adolescents $(N=1716)$. Minority adolescents were on average 15.60 years in wave one $(S D=1.25$, range: $13-20$ years $)$ and about half of them were boys $(46.4 \%)$. They were more often in vocational tracks $(51.3 \%)$ than professional or academic tracks. Minority adolescents were mostly second (79.8\%), but also first (18.0\%), and third generation. Majority adolescents were on average 15.08 years in

\footnotetext{
${ }^{1}$ The total data consisted of three waves, however, the measures we used were only repeated in wave two and three. We therefore could only use two waves.
} 
wave one $(S D=1.12$, range: $13-18$ years $)$ and half of them were boys $(50.0 \%)$. Majority adolescents were mainly in academic or professional tracks $(81.4 \%)$.

\section{Measures}

Acculturation orientations (T1, T2) referred to heritage culture maintenance and mainstream culture adoption orientations in the school context using the same single indicator for both minority and majority adolescents: 'Now think about all students with a migration background at your school. How important do you think it is that these students...', followed by '... maintain the customs of this other country at school?' for maintenance, and '....adopt the Belgian customs at school?' for adoption. Responses ranged from 1 (= Not important) to 4 (= Very important).

Peer acculturation norms $(\mathrm{T} 1)^{2}$ were calculated by aggregating the individual acculturation orientations of all students in school separately for mainstream culture adoption and heritage culture maintenance. General peer norms aggregate over Belgian majority, Turkish and Moroccan minority, as well as other minority pupils in the same schools with a view to fully and realistically reflect actual peer norms in culturally diverse school contexts.

School composition (T1) referred to the presence of majority youth and of Turkishand Moroccan-origin youth at school. Due to extreme skewness in the majority sample (Skewness $=-0.893, \mathrm{SD}=0.06$, Kurtosis $=0.466, \mathrm{SD}=0.12 ;$ MacCallum, Zhang, Preacher, \& Rucker, 2002), we created two dummy-coded variables using median-split . For consistency across models, we also used median-split for the minority sample in the main analyses reported here. For minorities, the median was 51.9 percent Turkish and Moroccan minorities in school. For majorities, the median was 71.2 percent majorities in school. We

\footnotetext{
${ }^{2}$ We focused on schools rather than classes for two reasons. First, it is common in secondary schools in Belgium to take courses with students from other classes and to change classes over time, so that peer networks typically extend beyond one's current classmates. Moreover, a three-level model with both gradelevel and school-level indicated that all contextual variance was located at the school level $\left(I C C_{\text {maintenance }}=0.08\right.$, $\left.I C C_{\text {adoption }}=0.06\right)$ rather than the grade level $\left(I C C_{\text {maintenance }}=0.00, I C C_{\text {adoption }}=0.01\right)$.
} 
also ran additional analyses with different threshold values (among the majority) and a continuous composition measure (among the minority) as a robustness check (see SOM).

Control variables (T1). Age, sex, and parental education (as a proxy for socioeconomic status) were added as control variables. We also controlled for school track, because minority adolescents are more often in vocational tracks than majority adolescents (cf. supra; Baysu et al., 2018). For parental education, the measure ranged from $0=N o$ formal education to $3=$ Higher vocational/university education, using the parent with the highest education as the decisive score. For school track, we used a dichotomous variable being $0=$ vocational secondary education and $1=$ academic or professional secondary education. We did not find significant effects of sex on acculturation orientations, which we dropped from the analyses.

\section{Analysis plan}

We estimated multi-level autoregressive cross-lagged panel models with two waves in a stepwise fashion using Mplus version 8.2 (Muthén \& Muthén, 1998-2017). First, individual acculturation orientations at time 1, together with parental education, school track, and age as controls, were entered as predictors of acculturation orientations at time 2 (the individual effects model). Next, main effects of the school-level variables were added for peer norm of adoption and maintenance and school composition (the school effects model). Lastly, all twoway interactions (two-way interaction model) and a three-way interaction (three-way interaction model) with school-level variables were added ${ }^{3}$.

\footnotetext{
${ }^{3}$ Additional model specifications: Models include all (co-)variances of individual adoption and maintenance and controls at T1, of individual adoption and maintenance at T2, and of school-level adoption and maintenance norms at T1. In the minority model, we fixed the variance of maintenance at T2 at the betweenlevel to 0.01 as it was not significant and fixed the non-significant covariance between individual adoption and maintenance at $\mathrm{T} 2$ at the between-level to 0 as they resulted in modelling issues. To improve model fit for the minority, we removed the non-significant control variables (i.e., school track and age), and removed the nonsignificant covariance between parental education and individual adoption and maintenance at the withinlevel. For the majority, we removed the non-significant control variables (i.e., parental education and age).
} 
Although autoregressive cross-lagged panel models do not test within-person change over time (i.e., increase or decrease), they are well-suited to test patterns of associations in line with compatibility or conflict over time. Specifically, lagged effects of T1 on T2 adoption and maintenance orientations indicate stability over time: a larger positive effect of $\mathrm{T} 1$ on $\mathrm{T} 2$ maintenance means that the distribution of maintenance orientations between respondents is more stable over time. To test our predictions, we focus on the cross-lagged effects: a significant effect of maintenance at T1 on adoption at T2 means that the distribution of maintenance at $\mathrm{T} 1$ explains the distribution of adoption orientations at $\mathrm{T} 2$, over and above the stability of adoption orientations over time. Therefore, significant positive cross-lagged effects indicate that maintenance and adoption orientations are mutually reinforcing over time - in line with the compatibility hypothesis for minority adolescents. Significant negative cross-lagged effects, on the other hand, indicate that maintenance and adoption orientations are attenuating each other over time - in line with the conflict hypothesis for majority adolescents. The cross-lagged effects are net of the covariance between acculturation orientations within time (which stand for compatibility or conflict within time).

\section{Results}

Descriptive statistics and sample comparisons of all variables can be found in Table 1. Out of the original 2863 participants, 1853 adolescents also participated one year later (drop-out rate of $35.3 \%$ ). There are no significant differences in acculturation orientations between these subsamples, so there is no evidence that our findings are biased by selective attrition. However, boys were more likely to drop out than girls $\left(\chi^{2}(1)=15.85, p<.001\right.$, Cramer's $\mathrm{V}=$ 0.07). Intra-class correlations of 0.06 for adoption and 0.08 for maintenance orientations indicate significant contextual variance between schools in adolescents' acculturation orientations.

\section{Main analyses}


Model comparisons. For the minority sample, the two-way interaction model is the final model $(\mathrm{CFI}=0.87, \mathrm{RMSEA}=0.062)$ since the three-way interaction did not significantly improve model fit (Table 2). For the majority sample, the school effects model is the final model $(\mathrm{CFI}=0.93, \mathrm{RMSEA}=0.079)$ since adding the interactions did not significantly improve model fit (Table 2).

Final minority model (Figure 1). Minority adolescents showed compatibility within time: Both at time $1(r=0.37, p<.001)$ and time $2(r=0.27, p<.001)$ maintenance and adoption orientations were positively correlated. Over time, both maintenance $(B=0.30, S E=$ $0.04, \beta=0.29, p<.001)$ and adoption orientations $(B=0.30, S E=0.05, \beta=0.32, p<.001)$ yield similar and moderate stability coefficients over a one-year period. Cross-lagged effects give partial support for compatibility over time (over and above compatibility within time): higher adoption orientations at time 1 were associated with higher maintenance orientations at time $2(B=0.07, S E=0.04, \beta=0.07, p=.038)$, but maintenance orientations at time 1 were dissociated from adoption orientations one year later. Thus, minority adolescents who initially valued mainstream culture adoption more, valued heritage culture maintenance more one year later (over and above stability in maintenance orientations). Furthermore, higher parental education predicted stronger adoption orientations over time $(B=0.11, S E=0.04, \beta$ $=0.09, p=.008)$. Explained variance in the individual acculturation orientations of minority adolescents over one year was significant yet small $\left(\mathrm{R}^{2}\right.$ maintenance $=0.10, \mathrm{R}^{2}$ adoption $\left.=0.11\right)$.

The school environment also made a difference for minority adolescents. Conditional on the presence of minority peers in school, peer norms of both maintenance $(B=0.65, S E=$ $0.33, \beta=0.63, p=.046$ for the interaction $)$ and adoption $(B=2.05, S E=0.65, \beta=0.82, \mathrm{p}=$ .002 for the interaction) predicted individual maintenance orientations over time. Figure 2 shows that a stronger maintenance norm in schools at time 1 predicts stronger individual maintenance orientations at time 2 (between schools with stronger (+1SD) vs. weaker (-1SD) 
maintenance norms; Wald $\left.\chi^{2}(1)=4.77, p=.029\right)$, but only in schools with a high presence of Turkish and Moroccan minority peers (Wald $\chi^{2}(1)=8.53, p=.004$ ). Figure 3 shows that stronger peer norms of adoption at time 1 predicts stronger individual maintenance orientations one year later (schools with strong (+1SD) vs weak (-1SD) adoption norms: Wald $\left.\chi^{2}(1)=7.99, p=.005\right)$, but only in schools with a greater presence of Turkish and Moroccan minority peers (Wald $\chi^{2}(1)=4.59, p=.032$ ). Significant normative effects mirror the individual-level acculturation pattern for minority adolescents, in line with compatibility over time. Hence, peer acculturation norms contribute to compatibility over time for minority adolescents, so that both their own earlier adoption orientation and the adoption norm of their peers positively predict stronger maintenance orientations over time. Explained variances at the school level were rather high $\left(R^{2}\right.$ maintenance $\left.=0.65, R_{\text {adoption }}^{2}=0.43\right)$ but note that intra-class correlations were rather small.

Final majority model (Figure 4) ${ }^{4}$. Majority adolescents showed conflict within time: Both at time $1(r=-0.10, p<.001)$ and time $2(r=-0.08, p=.005)$ maintenance and adoption orientations were significantly negatively correlated. Over time, the final majority model indicated similar and moderate stability over a one-year period for both maintenance $(B=$ $0.30, S E=0.03, \beta=0.30, p<.001)$ and adoption orientations $(B=0.39, S E=0.03, \beta=0.41$, $p<.001$ ). Cross-lagged effects fully support conflict over time (over and above conflict within time) for majority adolescents: higher adoption orientations at time 1 were associated with lower maintenance orientations at time $2(B=-0.13, S E=0.03, \beta=-0.12, p<.001)$; and a higher maintenance orientation at time 1 was associated with a lower adoption orientation at time $2(B=-0.08, S E=0.03, \beta=-0.10, p=.001)$. Thus, majority adolescents who valued minorities' adoption of the mainstream culture more at time 1, valued their maintenance of

\footnotetext{
${ }^{4}$ The final majority model was estimated using the Bayesian estimator in Mplus, because estimates were inconclusive between the unstandardized and standardized estimates. The Bayesian estimator gives more robust results in these cases. For the minority model, it was not necessary to use the Bayesian estimator, but results were robust whether we used it or not.
} 
the heritage culture (even) less at time 2. Similarly, those who valued minorities' maintenance of the heritage culture less at time 1, valued their adoption of the mainstream culture (even) more at time 2. Furthermore, majority students in academic tracks were less oriented towards maintenance over time $(B=-0.17, S E=0.09, \beta=-0.07, p=.029)$. Overall, explained variance in majority adolescents' individual acculturation orientations over one year was significant yet moderate $\left(\mathrm{R}^{2}\right.$ maintenance $\left.=0.12, \mathrm{R}_{\text {adoption }}=0.19\right)$.

At the school level, school composition was measured as relatively high or low shares of majority peers in school. A significant main effect of composition indicated that majority adolescents in schools with fewer majority peers (i.e., below the $71.2 \%$ median) reported (even) stronger adoption orientations at time $2(B=-0.13, S E=0.06, \beta=-0.41, p=.009)$. This finding suggests a possible reactive response of majority adolescents who might feel threatened by the greater presence of minority peers in highly-diverse schools. In addition, general peer norms of maintenance - but not adoption - had significant main effects on majority adolescents' individual orientations towards both maintenance and adoption at time 2. Controlling for school composition, general peer norms of maintenance were associated with stronger individual maintenance orientations $(B=0.27, S E=0.17, \beta=0.44, p=.049)$ as well as weaker individual adoption orientations one year later $(B=-0.27, S E=0.13, \beta=$ $0.62, p=.034)$. The latter finding mirrors our individual-level finding of conflict over time for majority youth. Thus, both their own earlier maintenance orientation and peer maintenance norms in their school predict weaker individual adoption orientations one year later. By implication, the more majority adolescents themselves and their peers in school reject heritage culture maintenance, the more they will stress mainstream culture adoption over time (over and above stability in their own adoption orientation). For majority adolescents, general peer norms of acculturation predicted their individual acculturation orientations over time regardless of school composition. Explained variances at the school 
level were rather high $\left(\mathrm{R}^{2}\right.$ maintenance $=0.36, \mathrm{R}^{2}$ adoption $\left.=0.68\right)$ but intra-class correlations were small.

\section{Additional analyses}

Below we summarize additional analyses to test for possible age differences; to exclude the possibility that general peer norms were driven by minority or majority group norms only; and to test the robustness of composition effects across different composition measures.

Age. We tested for age-related differences in acculturation patterns by adding interactions of both acculturation orientations with age at time 1. Age interactions did not improve model fit, nor did they explain additional variance in acculturation orientations at time 2 compared to the individual-level main effects model. We conclude that the data do not support a more fine-grained age-based differentiation of the longitudinal associations between acculturation orientations.

Subgroup norms. To test whether the contextual effects of general peer norms could be driven by either the majority subgroup or the Turkish and Moroccan minority subgroup, we reran the final models while replacing general peer norms with either majority or minority subgroup norms for majority and minority adolescents respectively. Adding subgroup norms at the school-level did not significantly improve model fit compared to the individual effects model $^{5}$, as distinct from models with general peer norms. Looking beyond global model fit, the only significant effect replicated an interaction of general adoption norms with composition in the minority sample with minority subgroup norms.

Composition effects. Main analyses of school composition using median-split were complemented by additional analyses with different composition measures as robustness

\footnotetext{
${ }^{5}$ For minority: The school effects model $(-2 * L L=16232.29, \mathrm{df}=47, \mathrm{AIC}=16326.29, \mathrm{BIC}=16563.40)$ showed worse model fit compared to the individual effects model $(-2 * \mathrm{LL}=16062.43, \mathrm{df}=36, \mathrm{AIC}=16134.43, \mathrm{BIC}=$ 16316.04, $\Delta \chi^{2}=$ n.s.). For majority: The school effects model $(-2 * L L=22895.09, d f=49, A I C=22993.09, B I C=$ 23260.03) showed worse model fit compared to the individual effects model $\left(-2^{*} \mathrm{LL}=22803.13, \mathrm{df}=38, \mathrm{AIC}=\right.$ 22879.13, $\mathrm{BIC}=23086.15, \Delta \chi^{2}=$ n.s.)
} 
checks (see SOM for more details). In the majority sample, we could not use the continuous composition measure because extreme skewness made it unreliable (MacCallum et al., 2002). However, we replicated the significant main effect of composition using alternate (and theoretically meaningful) threshold values (see SOM). In the minority sample, skewness was not an issue. Thus, the interaction effects of composition were fully replicated by significant quadratic interactions with a continuous composition measure (see SOM). Overall, additional analyses support the original findings for both minority and majority adolescents.

\section{Discussion}

Our study was set up to flesh out a dynamic and contextual approach of acculturation. Our findings articulate whether the heritage and mainstream cultural orientations of minority versus majority youth show distinct compatible versus conflicting patterns over time. Whereas consistent intergroup asymmetries in the acculturation orientations of minority and majority adolescents are well-documented (Brown \& Zagefka, 2011), it remained less clear how these asymmetries evolved over time and which role peer acculturation norms in school played in reinforcing or attenuating existing intergroup asymmetries. By drawing on largescale longitudinal, multi-level data of devalued Turkish- and Moroccan minority and Belgian majority adolescents in the same acculturative contexts (i.e., the same schools), we were able to compare how each group changes towards their respective intergroup positions in terms of their acculturation orientations. Furthermore, in support of the important role of peer norms during adolescence, we find that peer acculturation norms in the school contribute to these intergroup asymmetries over time.

Minority and majority acculturation orientations: compatible and conflicting over time First, by combining a developmental psychological perspective of adolescent development (see Titzmann \& Lee, 2018 for a review) with an intergroup relations perspective (Brown \& Zagefka, 2011), our findings demonstrate the dynamic nature of acculturation and its 
dependence on group membership. For minority adolescents, mainstream culture adoption reinforced heritage culture maintenance over time in partial support of compatibility. For majority adolescents, on the other hand, acculturation orientations became mutually exclusive. During adolescence, both minority and majority adolescents become aware of their respective unequal intergroup positions in society (Rubin et al., 2008) and of the corresponding intergroup attitudes and relations that come with this position (Killen, Mulvey et al., 2013; Rutland \& Killen, 2015). Our findings thus highlight that adolescence is a crucial period in which acculturation orientations evolve in line with intergroup inequalities and asymmetries in society.

Specifically, we found partial support that minority adolescents not only perceive their heritage culture as compatible with the mainstream culture within time, but also over time: those that initially valued adoption more, valued both adoption and maintenance orientations more one year later. In other words, if minority adolescents orient towards the mainstream culture, they also feel more accepted (Motti-Stefanidi, Pavlopoulos, \& Asendorpf, 2018) and more able to express their heritage culture in addition to the mainstream culture, facilitating integration over time (Schachner, Juang, et al., 2018; Schachner et al., 2017). Even though this effect was small over a one-year period, from a developmental perspective such small changes may amount to real differences in minority adolescents' integration over a longer period of time. As opposed to our expectations, we did not find that initial levels of maintenance were associated with adoption orientations one year later. The heritage culture is often an important source of social support for devalued minorities like Turkish- and Moroccan-origin adolescents (Voas \& Fleischmann, 2012). However, it seems that it does not help them to feel more accepted by the mainstream culture over time (Motti-Stefanidi et al., 2018). 
To the contrary, majority adolescents perceived, as expected, heritage culture maintenance of minorities as conflicting with the mainstream culture not only within time, but also over time: those who initially valued adoption more, valued adoption more but maintenance less one year later. The reverse was also true: those who initially valued maintenance more, valued maintenance more but adoption less one year later. This is in line with earlier cross-sectional findings, indicating that majority adolescents typically see the two cultural dimensions as conflicting (Arends-Tòth \& Van de Vijver, 2003; Brown \& Zagefka, 2011; Van Acker \& Vanbeselaere, 2012; Van Oudenhoven et al., 1998). Potentially, majority adolescents perceive heritage culture maintenance of their minority peers as a threat to, rather than an enrichment of, the mainstream culture (Piontkowski, Florack, Hoelker, \& Obdrzálek, 2000). As a result, they may expect their minority peers to choose between their heritage and the mainstream culture rather than allowing their minority peers to combine, and potentially blend, both cultures (Bourhis \& Dayan, 2004).

\section{The role of peer acculturation norms in culturally diverse schools}

Second, by combining ecological-systems theory approaches on the normative role of peers (Bronfenbrenner, 1979) with an intergroup relations perspective (Brown \& Zagefka, 2011), our findings show the contextual nature of acculturation across minority and majority groups. We show that peer norms play an important role in the development of acculturation orientations during adolescence and can have a different meaning for and affect change in acculturation orientations differently for minority and majority adolescents.

Following an ecological-systems theory approach (Bronfenbrenner, 1979), we demonstrated that acculturation orientations of adolescents are influenced by the orientations of their peers in school (Motti-Stefanidi et al., 2012; Schachner, Juang, et al., 2018; Schachner et al., 2017). For minority adolescents, interestingly, peer norms of both maintenance and adoption were predictive of increased maintenance one year later, but only 
in schools with large shares of other Turkish and Moroccan minority peers. Whereas we expected the normative influence of peer maintenance norms, we also find that peer adoption norms help minority adolescents to express their heritage culture as well in schools with sufficient shares of minority peers. This is in line with the compatibility hypothesis and implies that in these schools, a stronger norm of adoption does not come at the cost of expectations of relinquishing the heritage culture. Along the same lines, whereas in the total minority sample there is a strong negative correlation between the two norms $(r=-0.46, p<$ $.001)$, in schools with large shares of minority peers the correlation is weakly positive $(r=$ $0.09, p=.037$; in schools with low shares of minority peers: $r=-0.42, p<.001$ ). In most Belgian schools, a mainstream culture orientation is valued at the expense of minority adolescents' heritage cultures (Celeste, Baysu, Phalet, Meeussen, \& Kende, 2019). We find the same pattern for peer acculturation norms in schools with relatively few minority peers. However, it turns out that there is something uniquely positive about the schools with large shares of minority peers: additional analyses reveal that these schools almost all have a peer norm of integration, which helps minority adolescents to value and express their heritage cultures at school, over and beyond their mainstream culture orientations (Schachner, Juang, et al., 2018; Schachner et al., 2017). Having sufficient shares of minority peers therefore seems to be a boundary condition for minority adolescents to be able to increasingly express their heritage culture at school (Rock et al., 2011) in light of both peer norms of maintenance and adoption. This is in line with evidence on the positive effects of minority peer presence such as experiencing more pride about their heritage culture (Leszczensky et al., 2017) and feeling safer and more accepted by their peers (Asendorpf \& Motti-Stefanidi, 2017; Juvonen et al., 2018).

Majority adolescents, on the contrary, who are in schools with peers who value heritage culture maintenance of minorities (i.e., regardless of the composition), increasingly 
value heritage culture maintenance of their minority peers as well but at the same time they start to consider it less important that their minority peers are part of the mainstream culture. While the former shows the expected normative influence of peer maintenance norms on individual maintenance orientations, the latter mirrors the conflict pattern in the individual acculturation orientations of majority adolescents. This may be a way for majority adolescents to reject their minority peers if they want to maintain their heritage culture (Celeste et al., 2016). We also found a direct effect of school composition: majority adolescents who were in schools with relatively large shares of minority peers would increase their individual adoption orientations one year later. This could be a reactive response of majority adolescents who feel threatened by the large minority peer presence (see Riek, Mania, \& Gaertner, 2006 for a review). We did not find an interaction effect between school composition and peer acculturation norms for majority adolescents. A norm of adoption is the default in the school context and is not threatening for majorities regardless of who comprises the norm. By implication, in the eyes of majorities, a strong norm of maintenance, then, in and by itself poses a threat to their (mainstream) culture, no matter the composition of the school.

We did not find effects of either peer acculturation norms on individual adoption orientations of minority adolescents and no effects of peer adoption norms on either individual cultural orientation of majority adolescents. We speculate that this is due to the prevailing diversity climate in Belgian schools, where heritage cultures of minorities are often devalued and disregarded and mainstream culture adoption is expected (Celeste et al., 2019). Against this background, for minority adolescents, peer acculturation norms in the school mainly make a difference in enabling minority adolescents to express their heritage culture in school but does not facilitate or hinder minority adolescents' mainstream culture adoption over time. Similarly, for majority adolescents, mainly peer norms of maintenance 
vary in their schools, as peer norms of adoption were generally strong (i.e., almost all above the midpoint of the scale with an average of 3.06 on a 4-point scale).

\section{Wider implications and future directions}

Our findings combined indicate clear and consistent intergroup asymmetries of what each group desires in terms of minorities' acculturation orientations. For minority adolescents, it is an "and-and" situation, whereas for majority adolescents it is an "either-or" situation.

Whereas minority adolescents' mainstream culture adoption helps them to express their heritage culture in school, majority adolescents will either stress mainstream culture adoption or heritage culture maintenance, but not both. While distinct compatible vs. conflicting acculturation patterns are already in place in minority vs. majority adolescents in our study, peer acculturation norms are revealed as one significant contextual factor that contributes to the further socialization of adolescents into asymmetric minority vs. majority group positions. More generally, this has important implications because these asymmetries in acculturation orientations of majority and minority groups can result in tense intergroup relations (Bourhis et al., 1997) and negative mutual intergroup attitudes (Brown \& Zagefka, 2011; Celeste et al., 2014; Pfafferott \& Brown, 2006). Additionally, these asymmetric acculturation patterns have psychological costs for minority adolescents, like more acculturative stress, less successful socio-cultural adaptation, lower self-esteem (Kunst \& Sam, 2013), lower life satisfaction (Pfafferott \& Brown, 2006), and more experiences of peer rejection (Celeste et al., 2016). Furthermore, this leaves minorities in the position where they are expected by their majority peers to choose between both cultures. This has important implications as well, since the adaptive benefits of integration hinge upon a supportive wider environment (Phalet \& Baysu, Forthcoming). Therefore, conflicting majority orientations can be psychologically costly for minority adolescents, and leaves especially those who strive to combine the cultures vulnerable (e.g. Baysu, Phalet, \& Brown, 2011; Celeste et al., 2016). We do not know, 
however, whether the observed patterns of compatibility and conflict are specifically related to the relative centrality of the mainstream culture in the school context. Future research may therefore extend our findings beyond the school context and add on the (interplay with the) family context as well. Additionally, future research could look into other contextual developmental factors beyond the peer context, such as possible delayed or prolonged effects of parental acculturation orientations for instance, to further advance our understanding of distinct and diverging acculturation patterns among minority versus majority adolescents.

Our study also has wider theoretical and practical implications. Promoting peer norms of (adoption and) maintenance may be an important step to take, so that minority adolescents can increasingly combine both cultural orientations with the support of their majority peers. However, these beneficial effects for minorities seem to occur only in schools with large shares of minority peers (for now). It thus seems that minority peers play an important role in shaping minority adolescents' acculturation orientations over time. Most research on peer norms in developmental psychology, however, does not distinguish different ethnic peer groups (Graham et al., 2009). Our results hint at unique contributions of both minority and majority peers in the development of adolescents' acculturation orientations. Future research should zoom into the unique formative role of ethnic minority peers in acculturation processes of both minority and majority adolescents.

Future studies should also start to understand how peer norms can help increase support for integration from majority adolescents as well. Our results indicate that promoting stronger peer norms of maintenance may on the one hand increase support for heritage culture maintenance, but on the other hand may pave the way for majority preferences for weaker adoption orientations. Future (experimental) studies could potentially shed light on which factors can contribute to or hinder positive effects of peer acculturation norms on minority and majority adolescents' support for integration. To achieve this, it may be 
worthwhile to promote compatibility for majority acculturation orientations. This could be achieved by helping majority adolescents develop stronger prosocial intergroup attitudes (Aronson \& Brown, 2013) and lower prejudice (Zagefka et al., 2014), by promoting mutual understanding between minority and majority adolescents (Berger, Brenick, Lawrence, Coco, \& Abu-Raiya, 2018) and by discussing how minority groups enrich the culture, rather than portraying minority groups as a threat (see Berger, et al., 2018 for promising future routes). Future applied and experimental research thus should invest in understanding how to increase compatibility between majority acculturation orientations of children and youth alike.

\section{Limitations}

Our study also has limitations. First, who adolescents had in mind when answering our questions regarding their acculturation orientations remains less clear. For minority adolescents, it is likely that they will think of their own heritage culture, but for majority adolescents it is less clear which heritage culture(s) they thought of. Potentially, majority adolescents thought of students who belong to a visible and devalued minority group, like Turkish and Moroccan minorities (Voas \& Fleischmann, 2012). Since majorities have different acculturation preferences for minorities of devalued versus valued groups (Bourhis \& Dayan, 2004), this might have implications for the conflicting patterns of acculturation found in this study. Future research should replicate the present findings when asking adolescents about specific minority groups. Also, we aggregated individual acculturation orientations at the school-level, therefore it remains unclear which peers are the most influential. For example, while adolescents often befriend peers with a similar ethnic background (Smith, Maas, \& van Tubergen, 2014) and with a similar ethnic identity (Jugert, Leszczensky, \& Pink, 2018), intergroup friendships are associated with lower prejudice (Gaias, Gal, Abry, Taylor, \& Granger, 2018), more acceptance and less rejection of minority peers, and more positive intergroup attitudes (Hunter \& Elias, 1999). It is thus likely that 
(intra- or intergroup) friends influence adolescents' acculturation orientations in addition to their peers in general. Additionally, cross-lagged panel models cannot differentiate withinand between-person processes (e.g. Hamaker, Kuiper, \& Grasman, 2015). Compared to other longitudinal models, which require at least three waves of data and can model change (see Hamaker et al., 2015 for some suggestions), our analytical approach limits any causal or change-related inferences between individual acculturation orientations but it is best suited to the analysis of two-wave data. Additionally, our results showed low stability coefficients and small explained variances at both the within- and between-level. While low-stability in acculturation orientations might indicate significant change over the scope of one year, future research should aim to replicate our findings using other statistical approaches with more waves of data.

In sum, reflecting the complex everyday reality of multicultural schools, our results shed light on the day-to-day intergroup processes which shape acculturation orientations of minority and majority adolescents. Minority and majority adolescents have different patterns of acculturation orientations, and these differences augment over time. Peer norms of acculturation can help minority adolescents to combine their heritage with the mainstream culture. However, the same norms can increase the conflict for majority adolescents, which may eventually result in an unwelcoming environment for their minority peers. There is an important message for schools here, that is, to provide a safe environment for all: Where minority adolescents can value and express their cultures, but where majority adolescents still feel welcome and do not experience increased (cultural) threat from their minority peers.

\section{References}

Arends-Tòth, J., \& Van de Vijver, F.J.R. (2003). Multiculturalism and acculturation: Views of Dutch and Turkish-Dutch. European Journal of Social Psychology, 33, 249-266. doi:10.1002/ejsp.143 
Aronson, K.M., \& Brown, R. (2013). Acculturation and social attitudes among majority children. International Journal of Intercultural Relations, 37, 313-322. doi:10.1016/j.ijintrel.2013.02.004

Asendorpf, J.B., \& Motti-Stefanidi, F. (2017). Immigrant status, immigrant composition of the classroom, and acculturation. Cultural Diversity and Ethnic Minority Psychology, 23, 486-498. doi:10.1037/cdp0000155

Baysu, G., Alanya, A., \& De Valk, H.A.G. (2018). School trajectories of the second generation of Turkish immigrants in Sweden, Belgium, Netherlands, Austria, and Germany: The role of school systems. International Journal of Comparative Sociology, 59, 451-479. doi:10.1177/0020715218818638

Baysu, G., Phalet, K., \& Brown, R. (2011). Dual identity as a two-edged sword: Identity threat and minority school performance. Social Psychology Quarterly, 74, 121-143. doi:10.1177/0190272511407619

Benet-Martínez, V., Leu, J., Lee, F., \& Morris, M.W. (2002). Negotiating biculturalism: Cultural frame switching in biculturals with oppositional versus compatible cultural identities. Journal of Cross-Cultural Psychology, 33, 492-516. doi:10.1177/0022022102033005005

Berger, R., Brenick, A., Lawrence, S.E., Coco, L., \& Abu-Raiya, H. (2018). Comparing the effectiveness and durability of contact- and skills-based prejudice reduction approaches. Journal of Applied Developmental Psychology, 59, 46-53. doi:10.1016/j.appdev.2018.04.002

Berry, J.W. (1997). Immigration, acculturation, and adaptation. Applied Psychology: An International Review, 46, 5-68.

Berry, J. W., Phinney, J. S., Sam, D. L., \& Vedder, P. (2006). Immigrant youth in cultural transition. Mahwah, NJ: Lawrence Erlbaum Associates. 
Bourhis, R.Y., \& Dayan, J. (2004). Acculturation orientations towards Israeli Arabs and Jewish immigrants in Israel. International Journal of Psychology, 39, 118-131. doi:10.1080/00207590344000358

Bourhis, R. Y., Moïse, L. C., Perreault, S., \& Senecal, S. (1997). Towards an interactive acculturation model: A social psychological approach. International Journal of Psychology, 32, 369 - 386. doi:https://doi.org/10.1080/002075997400629

Brechwald, W.A., \& Prinstein, M.J. (2011). Beyond homophily: A decade of advances in understanding peer influence processes. Journal of Research on Adolescence, 21, 166179. doi:10.1111/j.1532-7795.2010.00721.x.

Bronfenbrenner, U. (1979). The ecology of human development: Experiments by nature and design. Cambridge, Massachusetts: Harvard University Press.

Brown, R., Baysu, G., Cameron, L., Nigbur, D., Rutland, A., Watters, C., ... \& Landau, A. (2013). Acculturation attitudes and social adjustment in British South Asian children: A longitudinal study. Personality and Social Psychology Bulletin, 39, 1656-1667. doi:10.1177/0146167213500149

Brown, R. \& Zagefka, H. (2011). The dynamics of acculturation: An intergroup perspective. Advances in Experimental Social Psychology, 44, 129-184. doi:10.1016/B978-0-12385522-0.00003-2

Celeste, L., Baysu, G., Phalet, K., Meeussen, L., \& Kende, J. (2019). Can school diversity policies reduce belonging and achievement gaps between minority and majority youth? Multiculturalism, colorblindness, and assimilationism assessed. Personality and Social Psychology Bulletin. Advance online publication. doi:10.1177/0146167219838577

Celeste, L., Brown, R., Tip, L.K., \& Matera, C. (2014). Acculturation is a two-way street: Majority-minority perspectives of outgroup acculturation preferences and the 
mediating role of multiculturalism and threat. International Journal of Intercultural Relations, 43, 304-320. doi:10.1016/j.ijintrel.2014.10.002

Celeste, L., Meeussen, L., \& Verschueren, K., \& Phalet, K. (2016). Minority acculturation and peer rejection: Costs of acculturation misfit with peer-group norms. British Journal of Social Psychology, 55, 544-563. doi:10.1111/bjso.12147

Fleischmann, F., \& Phalet, K. (2016). Identity conflict or compatibility: A comparison of Muslim minorities in five European cities. Political Psychology, 37, 447-463. doi:10.1111/pops. 12278

Fuller-Rowell, T.E., Ong, A.D., \& Phinney, J.S. (2013). National identity and perceived discrimination predict changes in ethnic identity commitment: Evidence from a longitudinal study of Latino college students. Applied Psychology: An international Review, 62, 406-426. doi:10.1111/j.1464-0597.2012.00486.x

Gaias, L.M., Gal, D.E., Abry, T., Taylor, M., \& Granger, K.L. (2018). Diversity exposure in preschool: Longitudinal implications for cross-race friendships and racial bias. Journal of Applied Developmental Psychology, 59, 5-15. doi:10.1016/j.appdev.2018.02.005

Gharaei, N., Thijs, J., \& Verkuyten, M. (2019). Ethnic identity in diverse schools: Preadolescents' private regard and introjection in relation to classroom norms and composition. Journal of Youth and Adolescence, 48, 132-144. doi:10.1007/s10964018-0881-y

González, R., Lickel, B., Gupta, M., Tropp, L.R., Luengo Kanacri, B.P., Mora, E., ..., Bernardino, M. (2017). Ethnic identity development and acculturation preferences among minority and majority youth: Norms and contact. Child Development, 88, 743760. doi:10.1111/cdev.12788 
Graham, S., Taylor, A. Z., \& Ho, A. Y. (2009). Race and ethnicity in peer relations research. In K. H. Rubin, W. M. Bukowski, \& B. Laursen (Eds.), Handbook of peer interactions, relationships, and groups (pp. 394-413). London: The Guilford Press.

Güngör, D., Bornstein, M.H., \& Phalet, K. (2012). Religiosity, values, and acculturation: A study of Turkish, Turkish-Belgian, and Belgian adolescents. International Journal of Behavioral Development, 36, 367-373. doi:10.1177/0165025412448357

Hamaker, E.L., Kuiper, R.M., \& Grasman, R.P.P.P. (2015). A critique of the cross-lagged panel model. Psychological Methods, 20, 102-116. doi:10.1037/a0038889

Heath, A., \& Brinbaum, Y. (2007). Explaining ethnic inequalities in educational attainment. Ethnicities, 7, 291-305. doi:10.1177/1468796807080230

Hunter, L., \& Elias, M.J. (1999). Interracial friendships, multicultural sensitivity, and social competence: How are they related? Journal of Applied Developmental Psychology, 20, 551-573. doi:10.1016/S0193-3973(99)00028-3

Jugert, P., Leszczensky, L., \& Pink S. (2018). The effects of ethnic minority adolescents' ethnic self-identification on friendship selection. Journal of Research on Adolescence, 28, 379-395. doi:10.1111/jora.12337|

Juvonen, J., Kogachi, K., \& Graham, S. (2018). When and how do students benefit from ethnic diversity in middle school? Child Development, 89, 1268-1282. doi:10.1111/cdev.12834

Killen, M., Mulvey, K.L., \& Hitti, A. (2013). Social exclusion in childhood: A developmental intergroup perspective. Child Development, 84, 772-790. doi:10.1111/cdev.12012

Killen, M., Rutland, A., Abrams, D., Mulvey, K.L., \& Hitti, A. (2013). Development of intraand intergroup judgments in the context of moral and social-conventional norms. Child Development, 84, 1063-1080. doi:10.1111/cdev.12011 
Kunst, J.R., \& Sam, D.L. (2013). Relationship between perceived acculturation expectations and Muslim minority youth's acculturation and adaptation. International Journal of Intercultural relations, 37, 477-490. doi:10.1016/j.ijintrel.2013.04.007

Leszczensky, L., Flache, A., Stark, T.H., \& Munniksma, A. (2017). The relationship between ethnic classroom composition and adolescents' ethnic pride. Group Processes \& Intergroup Relations, 21, 1-17. doi:10.1177/1368430217691363

MacCallum, R.C., Zhang, S., Preacher, K.J., \& Rucker, D.D. (2002). On the practice of dichotomization of quantitative variables. Psychological Methods, 7, 19-40. doi:10.1037//1082-989X.7.1.19

McGuire, L., Elenbaas, L., Killen, M., \& Rutland, A. (2018). The role of in-group norms and group status in children's and adolescents' decisions to rectify resource inequalities. British Journal of Developmental Psychology. Advance online publication. doi:10.1111/bjdp.12274

Meeussen, L., Delvaux, E., \& Phalet, K. (2014). Becoming a group: Value convergence and emergent work group identities. British Journal of Social Psychology, 53, 235-248. doi:10.1111/bjso.12021

Mesquita, B., De Leersnyder, J., \& Jasini, A. (2017). The cultural psychology of acculturation. In S. Kitayama \& D. Cohen (eds.). The Handbook of Cultural Psychology. New York, NY: Guilford Press.

Miklikowska, M. (2017). Development of anti-immigrant attitudes in adolescence: The role of parents, peers, intergroup friendships, and empathy. British Journal of Psychology, 108, 626-648. doi:10.1111/bjop.12236

Motti-Stefanidi, F., Berry, J., Chryssochoou, X., Sam, D.L., \& Phinney, J. (2012). Positive immigrant youth adaptation in context: Development, acculturation, and social psychological perspectives. In A.S. Masten, K. Liebkind, \& D.J. Hernandez (eds.), 
Realizing the potential of immigrant youth (pp. 117-158). New York, NY: Cambridge University Press.

Motti-Stefanidi, F., Pavlopoulos, V., \& Asendorpf, J.B. (2018). Immigrant youth acculturation and perceived discrimination: Longitudinal mediation by immigrant peers' acceptance/rejection. Journal of Applied Developmental Psychology, 59, 36-45. doi:10.1016/j.appdev.2018.03.001

Muthén, L.K. and Muthén, B.O. (1998-2017). Mplus User's Guide. Eighth Edition. Los Angeles, CA: Muthén \& Muthén

Nesdale, D., \& Mak, A.S. (2000). Immigrant acculturation attitudes and host country identification. Journal of Community \& Applied Social Psychology, 10, 483-495.

Pfafferott, I., \& Brown, R. (2006). Acculturation preferences of majority and minority adolescents in Germany in the context of society and family. International Journal of Intercultural Relations, 30, 703-717. doi:10.1016/j.ijintrel.2006.03.005

Phalet K., Andriessen I. (2004). Acculturation and educational attainment: Towards a contextual approach of minority school achievement. In: Hagendoorn L., Veenman J., Vollebergh W. (Eds.), Integrating Immigrants in the Netherlands: Cultural versus Socio-Economic Integration (pp. 145-172). Aldershot, UK: Ashgate.

Phalet, K., \& Baysu, G. (Forthcoming). Fitting in and standing out: How the intergroup context shapes minority acculturation and achievement. European Review of Social Psychology.

Phalet, K., Fleischmann, F., \& Hillekens, J. (2018). Religious identity and acculturation of immigrant minority youth: Toward a contextual and developmental approach. European Psychologist, 23, 32-43. doi:10.1027/1016-9040/a000309

Phalet, K., Meuleman, B., Hillekens, J., \& Sekaran, S. (2018). Leuven-CILS Technical Report Longitudinal 2012 - 2015. 
Piontkowski, U., Florack, A., Hoelker, P., \& Obdrzálek, P. (2000). Predicting acculturation attitudes of dominant and non-dominant groups. International Journal of Intercultural Relations, 24, 1-26. doi:10.1016/S0147-1767(99)00020-6

Riek, B.M., Mania, E.W., \& Gaertner, S.L. (2006). Intergroup threat and outgroup attitudes: A meta-analytic review. Personality and Social Psychology Review, 10, 336-353. doi:10.1207/s15327957pspr1004_4

Rivas-Drake, D., Saleem, M., Schaefer, D. R., Medina, M., \& Jagers, R. (2018). Intergroup Contact Attitudes Across Peer Networks in School: Selection, Influence, and Implications for Cross-Group Friendships. Child Development. Advance online publication. doi:10.1111/cdev.13061

Rock, P.F., Cole, D.J., Houshyar, S., Lythcott, M., \& Prinstein, M.J. (2011). Peer status in an ethnic context: Associations with African American adolescents' ethnic identity. Journal of Applied Developmental Psychology, 32, 163-169. doi:10.1016/j.appdev.2011.03.002

Rubin, K.H., Bukowski, W., Parker, J., \& Bowker, J.C. (2008). Peer interactions, relationships, and groups. In Damon, W. \& Lerner, R. (Eds), Developmental Psychology: An Advanced Course. New York: Wiley.

Rutland, A., \& Killen, M. (2015). A developmental science approach to reducing prejudice and social exclusion: Intergroup processes, social-cognitive development, and moral reasoning. Social Issues and Policy Review, 9, 121-154. doi:10.1111/sipr.12012|

Ryder, A. G., Alden, L. E., \& Paulhus, D. L. (2000). Is acculturation unidimensional or bidimensional? A head-to-head comparison in the prediction of personality, selfidentity, and adjustment. Journal of Personality and Social Psychology, 79, 49-65. doi:10.1037/0022-3514.79.1.49 
Schachner, M.K., Juang, L., Moffitt, U., \& Van de Vijver, F.J.R. (2018). Schools as acculturative and developmental contexts for youth of immigrant and refugee background. European Psychologist, 23, 44-56. doi:10.1027/1016-9040/a000312

Schachner, M.K., van de Vijver, F.J., \& Noack, P. (2018). Acculturation and school adjustment of early-adolescent immigrant boys and girls in Germany: Conditions in school, family, and ethnic group. Journal of Early Adolescence, 38, 352-384. doi:10.1177/0272431616670991

Schachner, M. K., van de Vijver, F. J., \& Noack, P. (2017). Contextual conditions for acculturation and adjustment of adolescent immigrants - Integrating theory and findings. Online Readings in Psychology and Culture, 8(1). doi:https://doi.org/10.9707/2307-0919.1142

Schwartz, S.J., Unger, J.B., Zamboanga, B.L., Córdova, D., Mason, C.A., Huang, S., ..., Szapocznik, J. (2015). Developmental trajectories of acculturation: Links with family functioning and mental health in recent-immigrant Hispanic adolescents. Child Development, 86, 726-748. doi:10.1111/cdev.12341

Smith, S., Maas, I., \& van Tubergen, F. (2014). Ethnic ingroup friendships in schools: Testing the by-product hypothesis in England, Germany, the Netherlands and Sweden. Social Networks, 39, 33-45. doi:10.1016/j.socnet.2014.04.003

Syed, M., Santos, C., Yoo, H. C., \& Juang, L. P. (2018). Invisibility of racial/ethnic minorities in developmental science: Implications for research and institutional practices. American Psychologist, 73, 812-826. doi:10.1037/amp0000294

Titzmann, P.F., \& Jugert, P. (2015). Acculturation in context: The moderating effects of immigrant and native peer orientations on the acculturation experiences of immigrants. Journal of Youth and Adolescence, 44, 2079-2094. doi:10.1007/s10964015-0314-0 
Titzman, P.F., \& Lee, R.M. (2018). Adaptation of young immigrants: A developmental perspective on acculturation research. European Psychologist, 23, 72-82. doi:10.1027/1016-9040/a000313

Van Acker, K., \& Vanbeselaere, N. (2012). Heritage culture maintenance precludes host culture adoption and vice versa: Flemings' perceptions of Turks' acculturation behavior. Group Processes \& Intergroup Relations, 15, 133-145. doi:10.1177/1368430211417263

Van Oudenhoven, J., Prins, K.S., \& Buunk, B.P. (1998). Attitudes of minority and majority members towards adaptation of immigrants. European Journal of Social Psychology, 28, 995-1013.

Voas, D., \& Fleischmann, F. (2012). Islam moves West: Religious change in the first and second generations. Annual Review of Sociology, 38, 525-545. doi:10.1146/annurevsoc-071811-145455

Vollebergh, W.A.M., Iedema, J., \& Raaijmakers, Q.A.W. (2001). Intergenerational transmission and the formation of cultural orientations in adolescence and young adulthood. Journal of Marriage and Family, 63, 1185-1198. doi:http://dx.doi.org/10.1111/j.1741-3737.2001.01185.x

Wölfer, R., Schmid, K., Hewstone, M., \& Van Zalk, M. (2016). Developmental dynamics of intergroup contact and intergroup attitudes: Long-term effects in adolescence and early adulthood. Child Development, 87, 1466-1478. doi:10.1111/cdev.12598

Zagefka, H., Binder, J., Brown, R., Kessler, T., Mummendey, A., Funke, F., ..., Maquil, A. (2014). The relationship between acculturation preferences and prejudice: Longitudinal evidence from majority and minority groups in three European countries. European Journal of Social Psychology, 44, 578-589. doi:10.1002/ejsp.2044 
Table 1. Descriptive Statistics per Subsample, Sample Comparisons, and Correlations per Subsample.

\begin{tabular}{|c|c|c|c|c|c|c|c|c|c|c|c|c|}
\hline & $\begin{array}{c}\text { Minority } \\
M(S D) / \\
\%\end{array}$ & $\begin{array}{c}\text { Majority } \\
M(S D) / \\
\%\end{array}$ & 1 & 2 & 3 & 4 & 5 & 6 & 7 & 8 & 9 & 10 \\
\hline 1. Adoption (T1) & $\begin{array}{c}2.79 \\
(0.93)\end{array}$ & $\begin{array}{c}3.16^{* * * *} \\
(0.85)\end{array}$ & --- & $0.42 * * *$ & $-0.10 * * *$ & $-0.16 * * *$ & $0.18 * * *$ & $-0.06^{*}$ & -0.03 & 0.05 & $0.06^{*}$ & 0.03 \\
\hline 2. Adoption (T2) & $\begin{array}{l}2.75 \\
(0.89)\end{array}$ & $\begin{array}{c}3.20 * * * \\
(0.81)\end{array}$ & $0.32 * * *$ & --- & $-0.15 * * *$ & $-0.17 * * *$ & $0.10 * *$ & $-0.09 * *$ & $-0.07 *$ & $0.09 * *$ & $0.08 * *$ & 0.02 \\
\hline 3. Maintenance (T1) & $\begin{array}{l}2.80 \\
(0.94)\end{array}$ & $\begin{array}{c}2.09 * * * \\
(0.94)\end{array}$ & $0.37 * * *$ & $0.10 *$ & --- & $0.32 * * *$ & $-0.06 *$ & $0.16 * * *$ & 0.02 & $-0.11 * * *$ & $-0.10 * * *$ & 0.01 \\
\hline 4. Maintenance (T2) & $\begin{array}{c}2.67 \\
(0.99)\end{array}$ & $\begin{array}{c}2.08^{* * *} \\
(0.95)\end{array}$ & $0.16 * * *$ & $0.30 * * *$ & $0.31 * * *$ & --- & $-0.12 * * *$ & $0.13 * * *$ & -0.01 & $-0.10 * *$ & $-0.10^{* *}$ & -0.03 \\
\hline $\begin{array}{l}\text { 5. Peer adoption } \\
\text { (T1) }\end{array}$ & $\begin{array}{c}2.89 \\
(0.15)\end{array}$ & $\begin{array}{c}3.06 * * * \\
(0.17)\end{array}$ & $0.09 * *$ & $0.10 * *$ & 0.01 & -0.01 & --- & $-0.37 * * *$ & $0.30 * * *$ & $-0.07 *$ & $0.18 * * *$ & $0.11 * * *$ \\
\hline $\begin{array}{l}\text { 6. Peer maintenance } \\
\text { (T1) }\end{array}$ & $\begin{array}{c}2.62 \\
(0.25)\end{array}$ & $\begin{array}{c}2.24 * * * \\
(0.24)\end{array}$ & -0.01 & 0.00 & $0.11 * * *$ & $0.08 *$ & $-0.46 * * *$ & --- & $-0.33 * * *$ & 0.01 & $-0.33 * * *$ & $-0.23 * * *$ \\
\hline $\begin{array}{l}\text { 7. Share of } \mathrm{min} / \mathrm{maj} \\
\text { - High }\end{array}$ & $50.4 \%$ & $49.7 \%$ & -0.03 & -0.07 & 0.02 & 0.03 & $-0.40 * * *$ & $0.55 * * *$ & --- & $-0.33 * * *$ & $0.17 * * *$ & $0.16^{* * * *}$ \\
\hline 8. Age & $\begin{array}{l}15.60 \\
(1.25)\end{array}$ & $\begin{array}{c}15.08 * * * \\
(1.12)\end{array}$ & 0.05 & -0.02 & 0.04 & -0.02 & 0.03 & 0.04 & 0.06 & --- & $-0.17 * * *$ & $-0.12 * * *$ \\
\hline $\begin{array}{l}\text { 9. Non-vocational } \\
\text { track }\end{array}$ & 48.7 & $81.4 * * *$ & -0.02 & 0.03 & -0.05 & -0.04 & $0.13 * * *$ & $-0.16 * * *$ & -0.03 & $-0.14 * * *$ & --- & $0.35 * * *$ \\
\hline $\begin{array}{l}\text { 10. Parental } \\
\text { education }\end{array}$ & $\begin{array}{c}1.96 \\
(0.77)\end{array}$ & $\begin{array}{c}2.51 * * * \\
(0.55)\end{array}$ & -0.02 & $0.10 *$ & -0.05 & -0.02 & 0.02 & $-0.08 * *$ & $-0.08 * *$ & $-0.09 * *$ & $0.15^{* * *}$ & --- \\
\hline
\end{tabular}

$* p<.05, * * p<.01, * * * p<.001$

Note. Correlations at the upper side of the diagonal are for majorities, on the lower side of the diagonal are for minorities. Asterisks at the descriptives of the majority sample indicate significant differences between minority and majority adolescents via t-test for continuous variables and chi-square for categorical variables. (No sample comparisons for the share of minority/majority peers as they were based on median-split) 
Table 2. Model Fit Comparisons for Both the Minority and Majority Subsample.

\begin{tabular}{|c|c|c|c|c|c|}
\hline & & $\begin{array}{l}\text { Individual } \\
\text { effects }\end{array}$ & School effects & $\begin{array}{l}\text { Two-way } \\
\text { interaction }\end{array}$ & $\begin{array}{l}\text { Three-way } \\
\text { interaction }\end{array}$ \\
\hline \multirow[t]{5}{*}{ Minority } & $-2 \mathrm{LL}$ & 16062.43 & 16037.52 & 16026.86 & 16022.26 \\
\hline & df & 36 & 47 & 53 & 55 \\
\hline & AIC & 16134.43 & 16131.52 & 16132.86 & 16132.26 \\
\hline & BIC & 16316.042 & 16368.63 & 16400.24 & 16407.73 \\
\hline & $\Delta \chi^{2}$ & -- & $\begin{array}{c}\Delta \chi^{2}(11)=25.23, \\
p=.008\end{array}$ & $\begin{array}{c}\Delta \chi^{2}(6)=17.53, \\
p=.008\end{array}$ & $\begin{array}{c}\Delta \chi^{2}(2)=1.53, \\
p=.466\end{array}$ \\
\hline \multirow[t]{5}{*}{ Majority } & $-2 \mathrm{LL}$ & 22803.13 & 22783.61 & 22785.51 & -- \\
\hline & Df & 38 & 49 & 55 & -- \\
\hline & AIC & 22879.13 & 22881.61 & 22895.51 & -- \\
\hline & $\mathrm{BIC}$ & 23086.15 & 23148.55 & 23195.14 & -- \\
\hline & $\Delta \chi^{2}$ & -- & $\begin{array}{c}\Delta \chi^{2}(11)=20.73, \\
p=.036\end{array}$ & n.s. & -- \\
\hline
\end{tabular}

Note. $-2 \mathrm{LL}=-2$ loglikelihood, AIC $=$ Akaike's information criterion, $\mathrm{BIC}=$ Bayesian information criterion, $\Delta \chi^{2}$ = robust Satorra-Bentler scaled chi-squared difference test 
Figure 1

Minority Final Model.

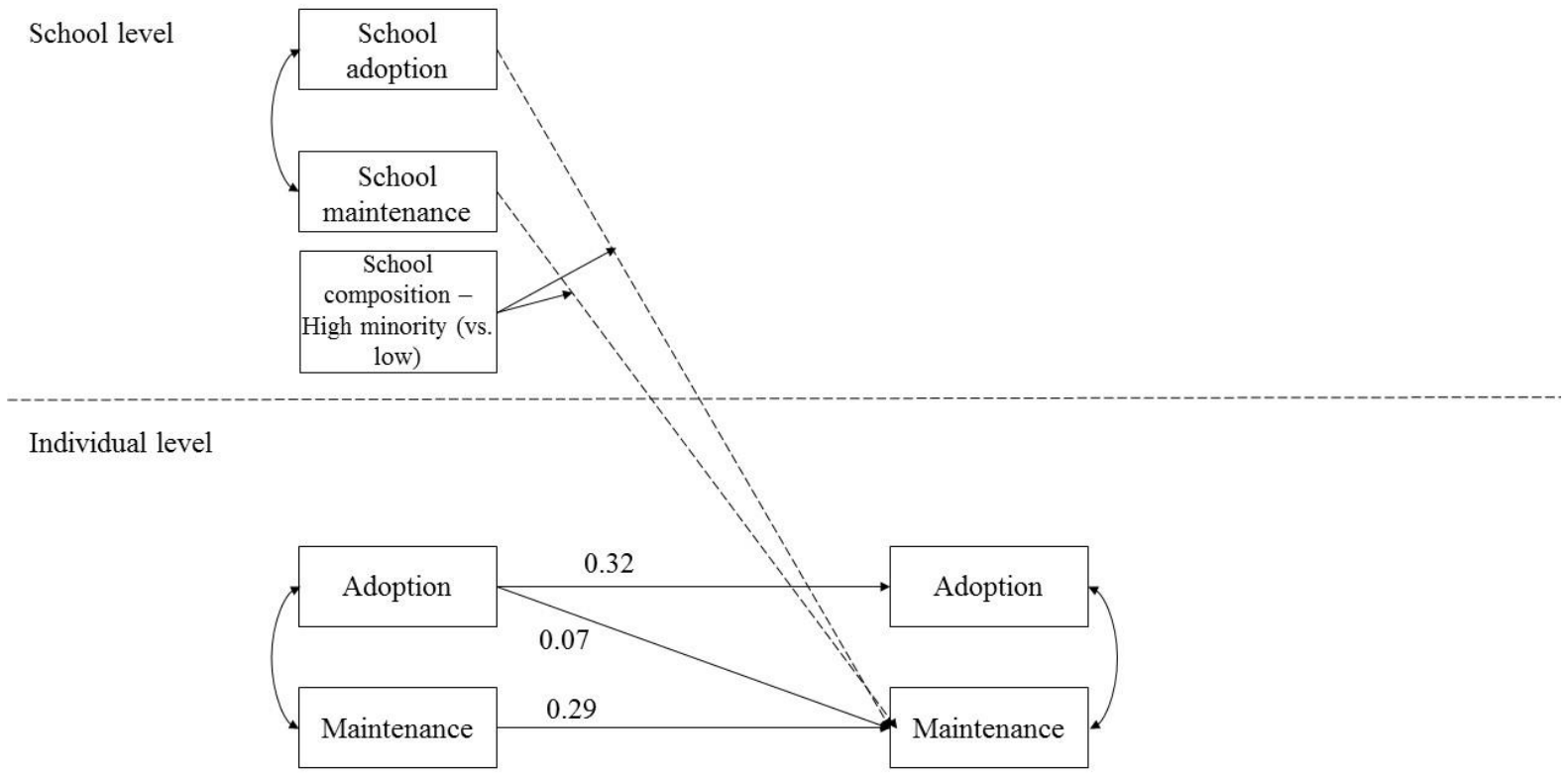

Note. Dashed lines are not significant, but part of significant interactions. Standardized estimates are displayed. Estimates are standardized using STDYX standardization. 
Figure 2

Interaction between Peer Maintenance X Minority Presence in Predicting Minority Maintenance.

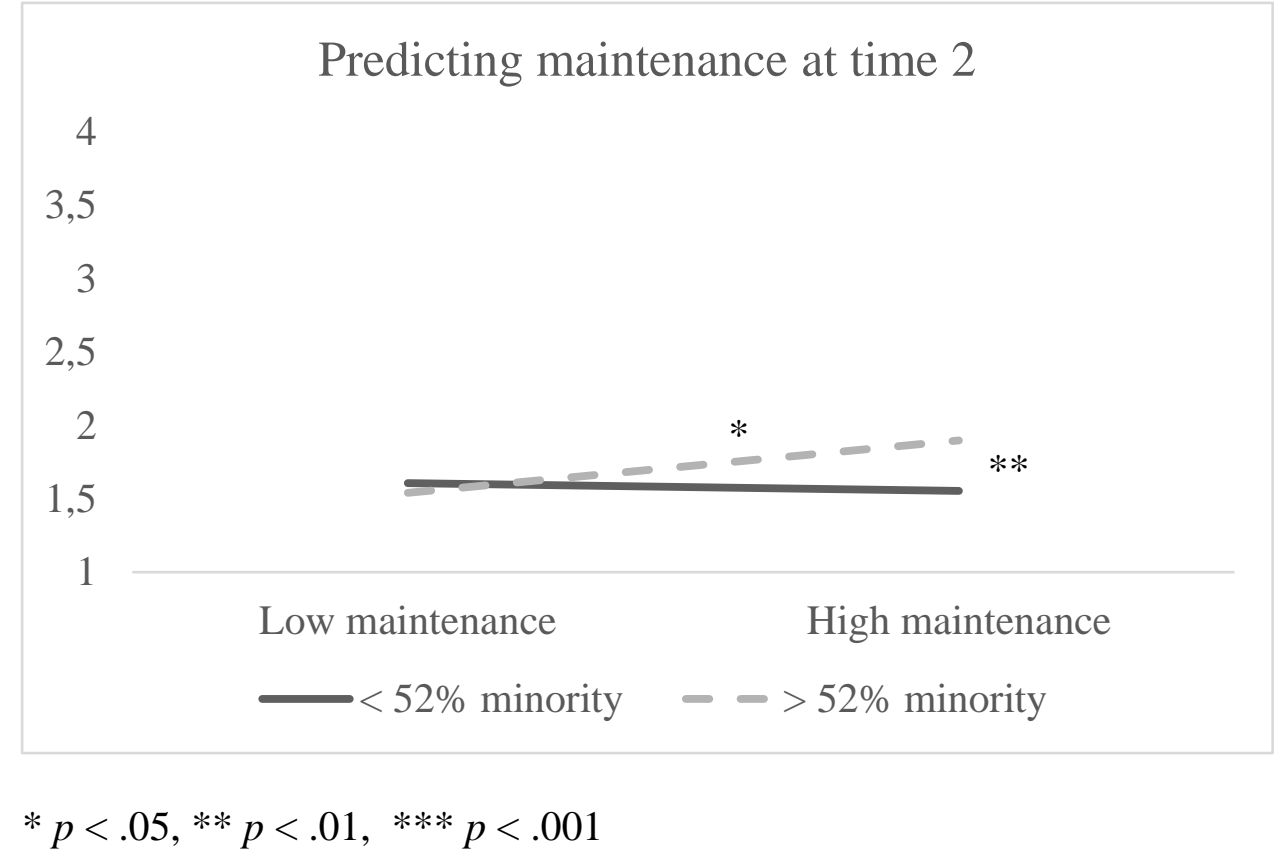


Figure 3

Interaction between Peer Adoption X Minority Presence in Predicting Minority Maintenance.

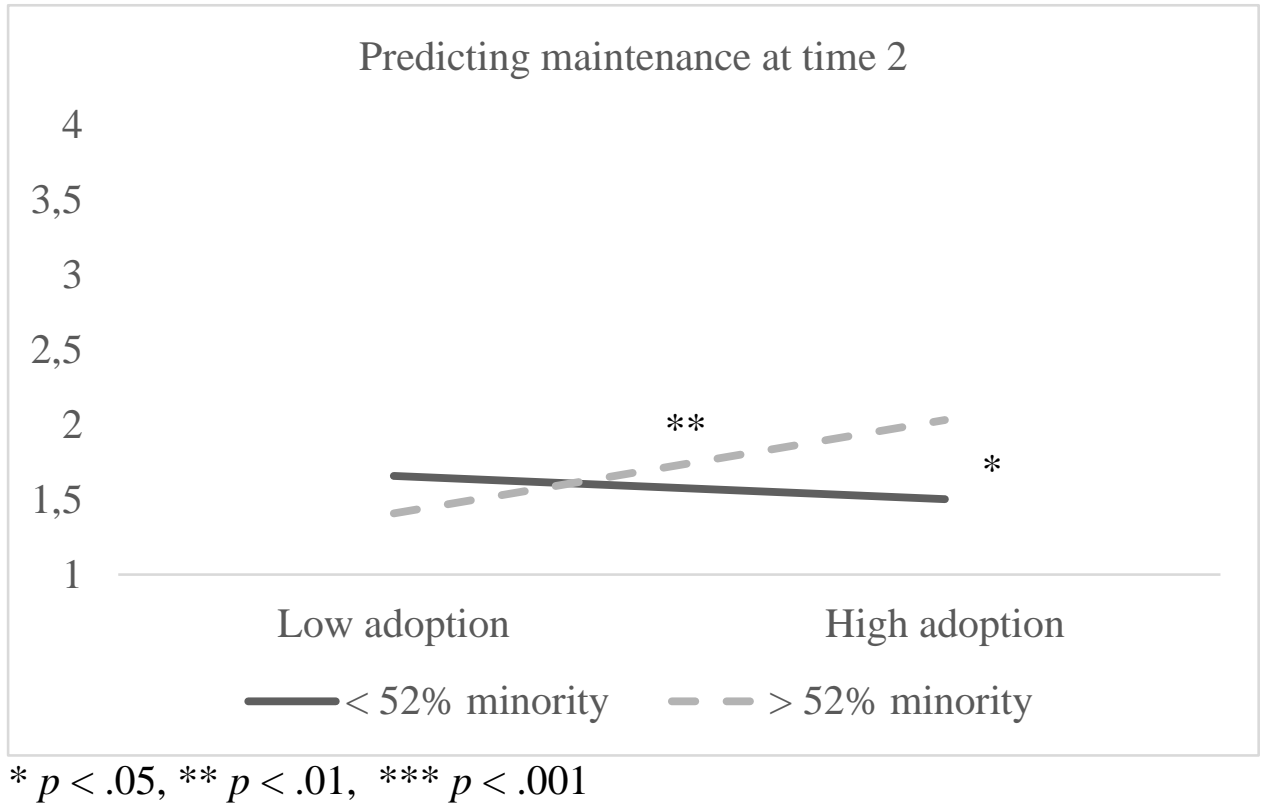


Figure 4

Majority Final Model.

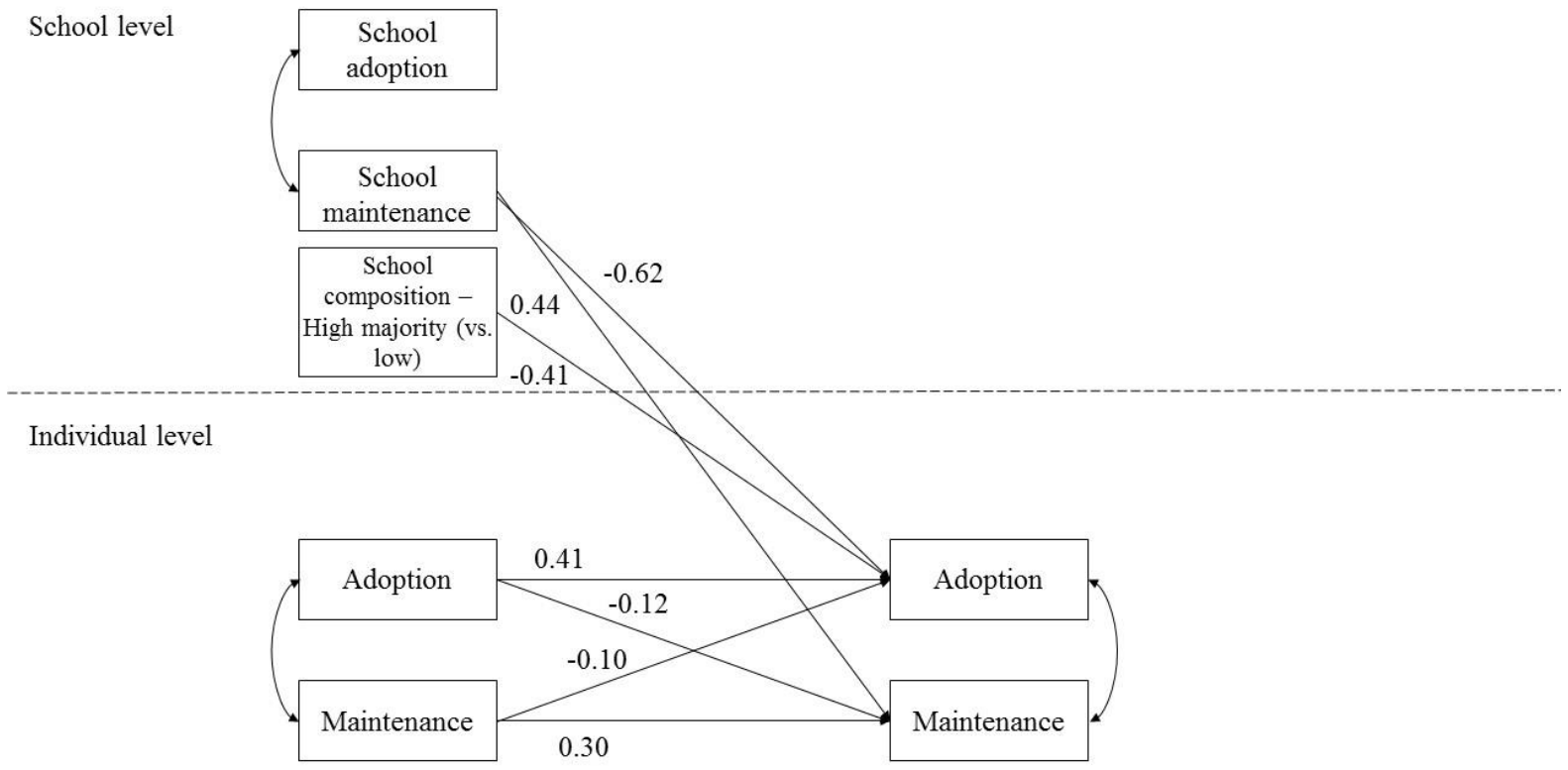

Note. Standardized estimates are displayed. Estimates are standardized using STDYX standardization. 


\section{Supplementary Online Materials}

\section{Different composition variables}

We compared minority adolescents in schools with $>60 \%$ Turkish-/Moroccan-minority pupils (clear numerical majority; reference category) with those in schools with 40-60\% minorities (around tipping point) and with $<40 \%$ minorities (clear numerical minority). Similarly, we distinguished between schools with $>60 \%, 40-60 \%$ and $>40 \%$ majority pupils for majority adolescents.

\section{Minority adolescents}

As can be seen in Table 1, the interactions as reported in the paper do not replicate using the different dummy coding (>60\%, 40-60\%, <40\% Turkish-/Moroccan-minority peers).

Supplementary Online Materials - Table 1. Final Model for Minority Adolescents using Other Dummy-Coded Variable

\begin{tabular}{lcc}
\hline & $B(S E)$ & $B(S E)$ \\
Individual-level & $\beta$ & $\beta$ \\
\hline Adoption T1 & Adoption T2 & Maintenance T2 \\
\cline { 2 - 3 } Maintenance T1 & $0.29(0.04)^{* * *}$ & $0.06(0.04)+$ \\
& 0.31 & 0.06 \\
Parental education & $-0.01(0.04)$ & $0.28(0.04)^{* * *}$ \\
& -0.01 & 0.27 \\
\hline School-level & $0.11(0.04)^{* *}$ & -- \\
\hline Peer norm adoption & 0.09 & \\
& & $1.32(1.71)$ \\
Peer norm maintenance & $3.16(2.14)+$ & 0.51 \\
& 0.58 & $0.91(0.94)$ \\
<40\% minority (vs. >60\%) & $-0.36(1.13)$ & 0.56 \\
& -0.12 & $0.05(0.53)$ \\
40-60\% minority (vs. >60\%) & $-0.59(0.66)$ & 0.04 \\
Norm adoption X norm & -0.27 & $-0.10(0.54)$ \\
maintenance & $-0.50(0.67)$ & -0.09 \\
Norm adoption X <40\% & -0.20 & $-0.02(1.54)$ \\
minority (vs. >60\%) & $0.52(1.87)$ & -0.00 \\
Norm adoption X 40-60\% & 0.02 & $-1.69(1.76)$ \\
minority (vs. >60\%) & $-2.73(2.24)$ & -0.51 \\
Norm maintenance X <40\% & -0.39 & $-0.96(1.68)$ \\
minority (vs. >60\%) & $-2.88(2.11)+$ & -0.15 \\
& -0.22 & $-0.73(1.01)$ \\
& $0.50(1.21)$ & -0.24 \\
& 0.10 & \\
& & \\
& &
\end{tabular}




\begin{tabular}{ccc} 
Norm maintenance X 40- & $0.62(1.20)$ & $-0.45(0.99)$ \\
$60 \%$ minority (vs. $>60 \%)$ & 0.09 & -0.11 \\
\hline$+p<.10, * p<.05, * * p<.01, * * * p<.001$ &
\end{tabular}

Note. Since unstandardized and standardized estimates yielded different results, we ran this model using a Bayesian estimator, which is more robust in these cases.

Next, we replicated the interaction effects of composition in the minority sample using a continuous measure $(\mathrm{CFI}=0.70, \mathrm{RMSEA}=0.079$; Table 2$)$. We found significant quadratic interaction effects of composition with peer norms, which replicated the interaction pattern with median-split in the paper and provide additional support for our original finding that in schools with higher shares of minority pupils, peer normative effects mirror a compatible acculturation pattern for minority adolescents (Figures 1-4; range graphs: 27.44\% - $73.56 \%$ with $M=50.50 \%$ and $+/-1 S D=23.06 \%$; we note that the mean and median (51.9\%) composition values are very similar among the minorities).

Supplementary Online Materials - Table 2. Final Model for Minority Adolescents using Continuous Composition and Squared Composition Measures

\begin{tabular}{lcc}
\hline & $B(S E)$ & $B(S E)$ \\
Individual-level & $\beta$ & $\beta$ \\
\cline { 2 - 3 } & Adoption T2 & Maintenance T2 \\
\cline { 2 - 3 } Adoption T1 & $0.29(0.04)^{* * *}$ & $0.06(0.04)+$ \\
Maintenance T1 & 0.31 & $0.29(0.04)^{* * *}$ \\
Parental education & $-0.00(0.04)$ & 0.28 \\
& -0.00 & -- \\
\hline School-level & $0.11(0.04)^{* *}$ & \\
\hline Peer norm adoption & 0.09 & $-0.50(0.39)$ \\
& & -0.33 \\
Peer norm maintenance & $0.09(0.41)$ & $-0.09(0.32)$ \\
& 0.05 & -0.10 \\
Share of Turkish/Moroccan & $-0.06(0.35)$ & $-0.00(0.04)$ \\
peers & -0.07 & -0.02 \\
Share of Turkish/Moroccan & $0.01(0.05)$ & $0.00(0.02)$ \\
peers - squared & 0.04 & 0.01 \\
Norm adoption X norm & $-0.01(0.02)$ & $1.88(1.62)$ \\
maintenance & -0.15 & 0.28 \\
Norm adoption X Share of & $1.05(1.68)$ & $-0.30(0.25)$ \\
Turkish/Moroccan peers & 0.14 & -0.34 \\
Norm adoption X Share of & $-0.42(0.28)+$ & $0.18(0.10) *$ \\
Turkish/Moroccan peers - & -0.46 & 0.80 \\
squared & $0.18(0.11)+$ &
\end{tabular}


Norm maintenance X Share $-0.24(0.20)$

$-0.43$

$0.05(0.17)$

of Turkish/Moroccan peers

$0.11(0.05)^{*}$

1.00

0.09

Norm maintenance X Share

of Turkish/Moroccan peers -

$0.06(0.05)+$

0.61

squared

$+p<.10, * p<.05, * * p<.01, * * * p<.001$

Note. Since unstandardized and standardized estimates yielded different results, we ran this model using a Bayesian estimator, which is more robust in these cases. 
Supplementary Online Materials - Figure 1. Interaction Effect of Composition (squared) with Maintenance at T1 on Maintenance at T2 for Minority Adolescents.

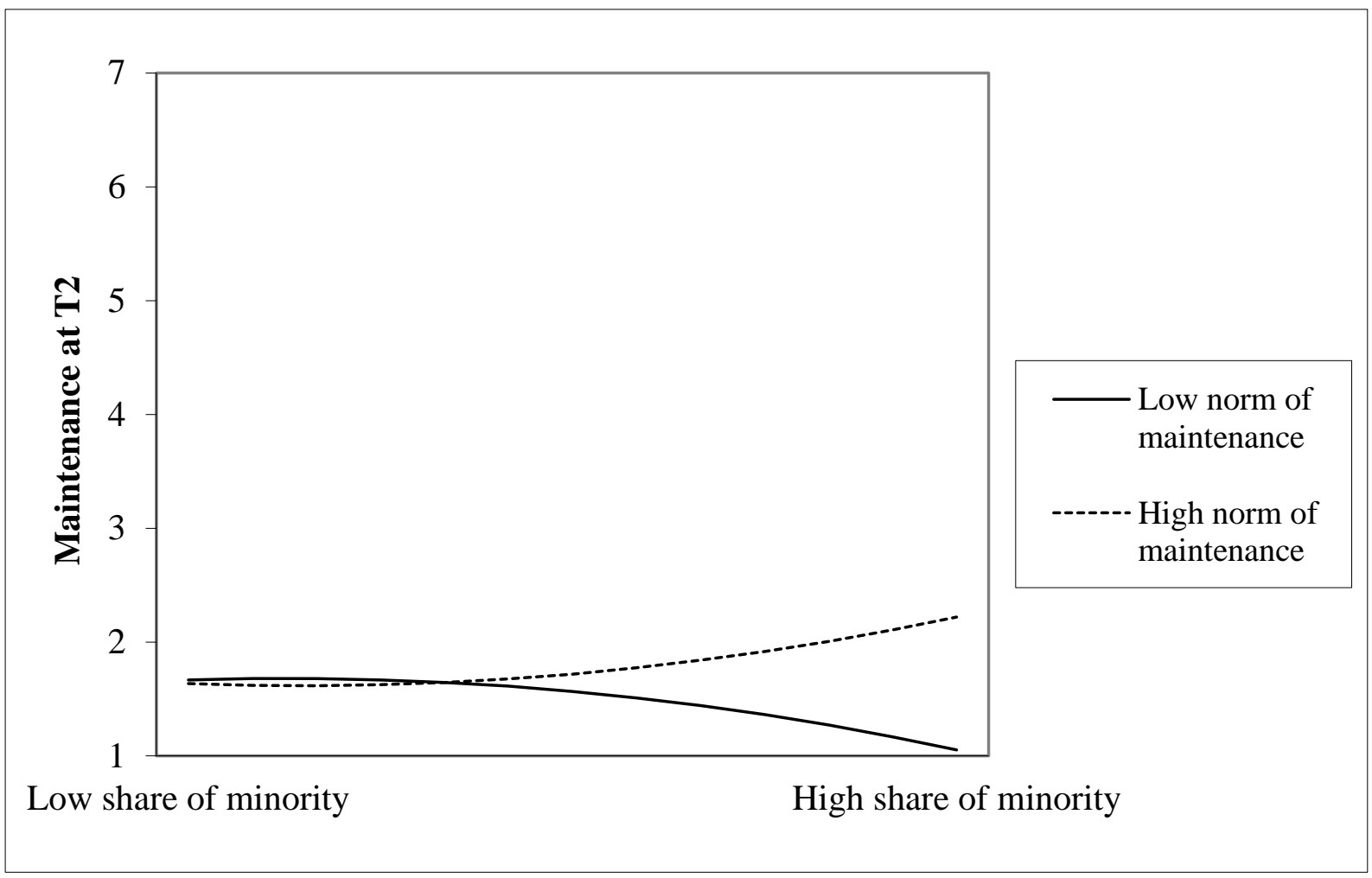

Supplementary Online Materials - Figure 2. Interaction Effect of Composition (Squared) with Adoption at T1 on Maintenance at T2 for Minority Adolescents.

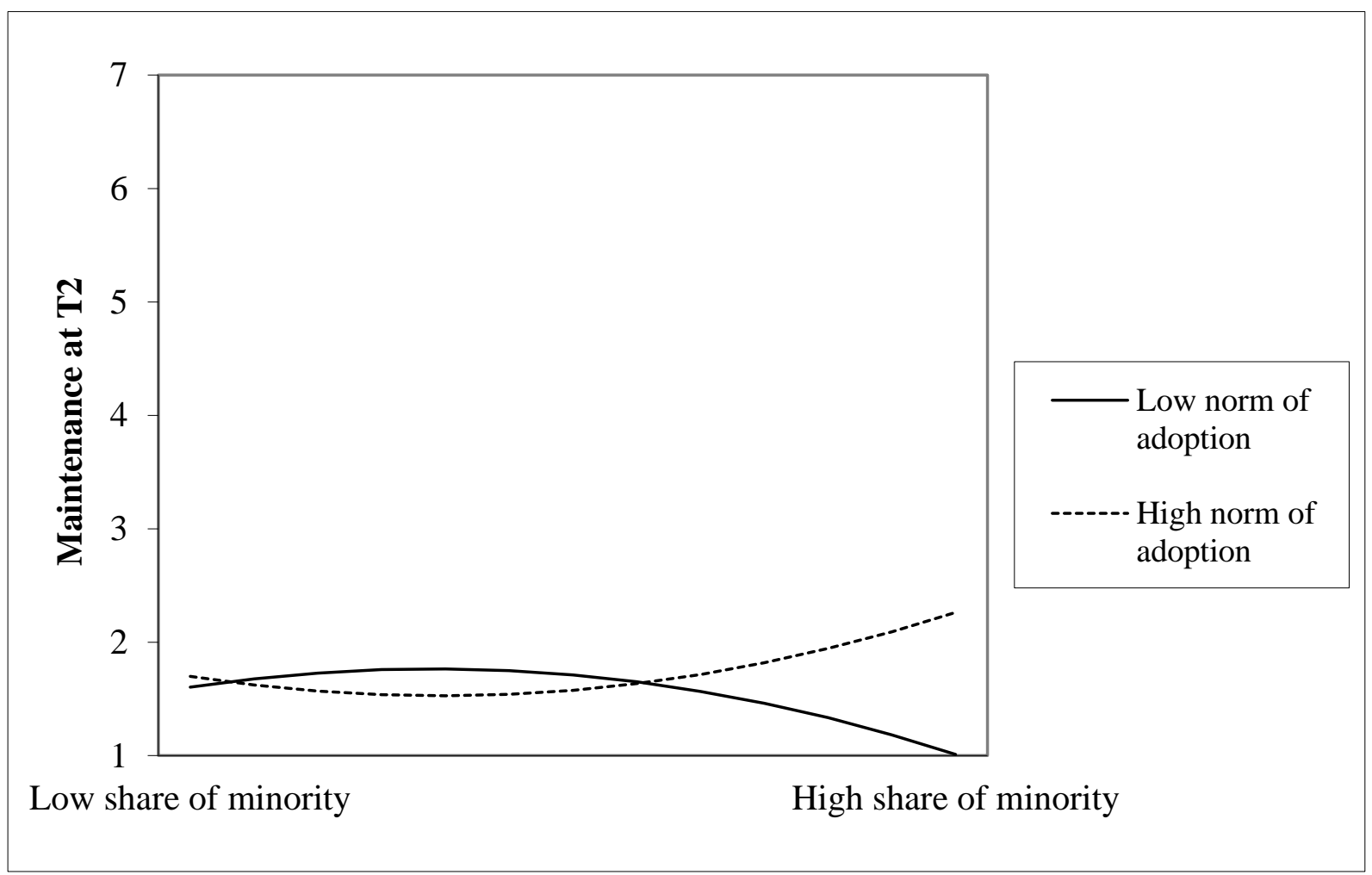


Supplementary Online Materials - Figure 3. Interaction Effect of Composition (Squared) with Adoption at T1 on Adoption at T2 for Minority Adolescents.

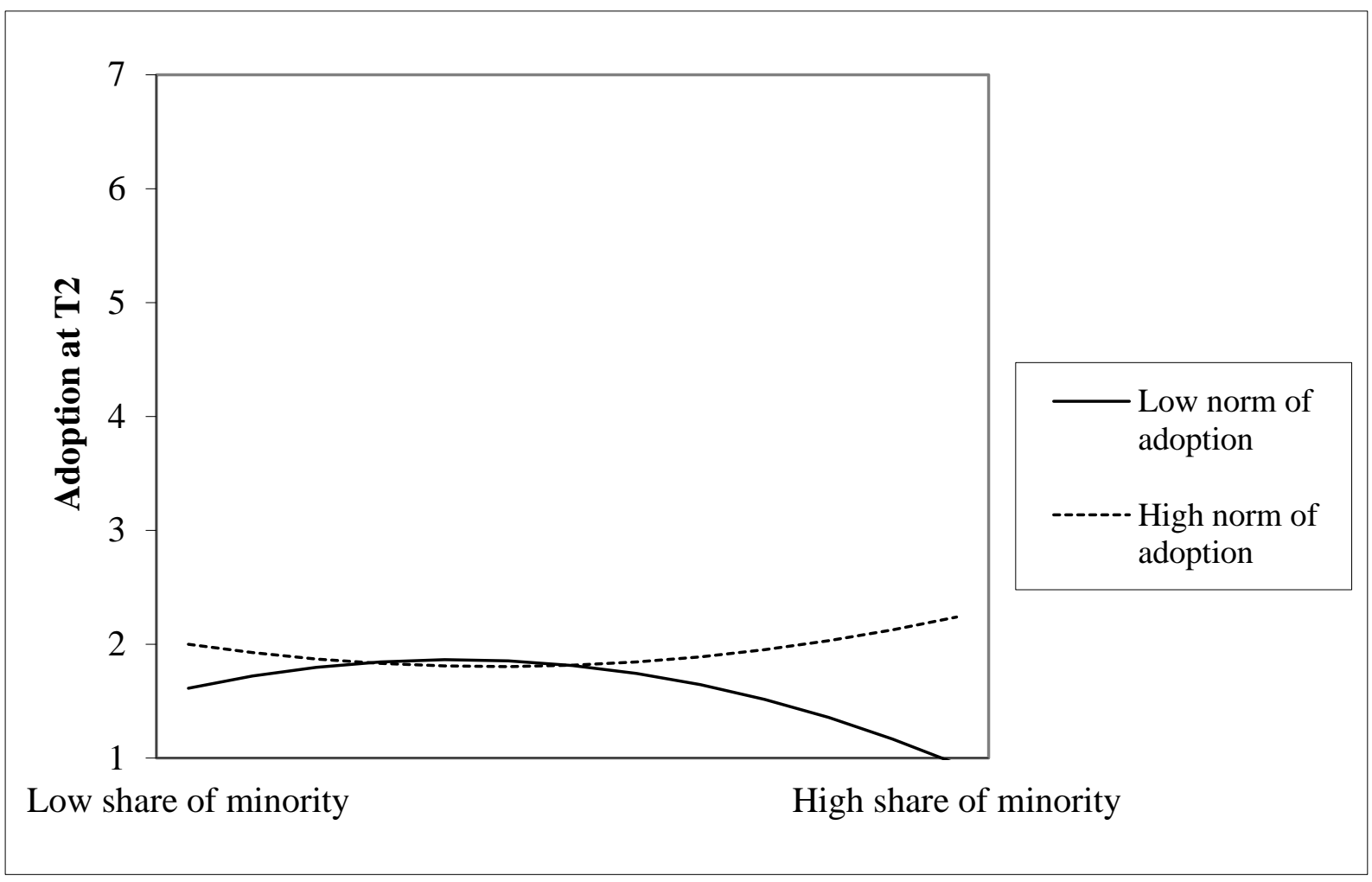

Supplementary Online Materials - Figure 4. Interaction Effect of Composition (Squared) with

Maintenance at T1 on Adoption at T2 for Minority adolescents.

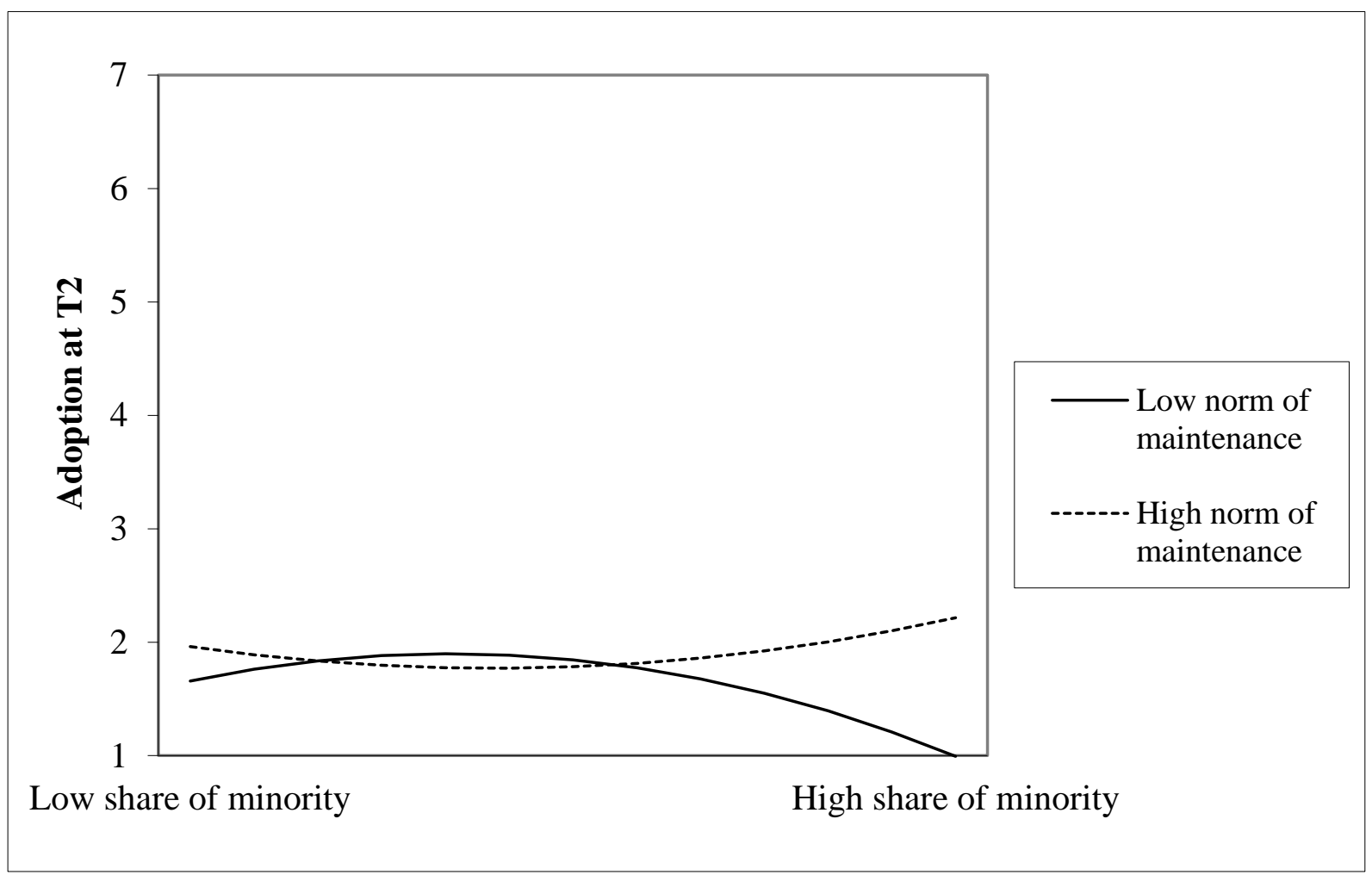




\section{Majority adolescents}

As can be seen in Table 3, the main effect of composition with median-split was replicated using a different dummy coding $(>60 \%, 40-60 \%,<40 \%$ majority peers; $\mathrm{CFI}=0.84$; RMSEA $=0.098)$. In the majority sample extreme skewness due to ethnic school segregation precludes accurate significance tests with a continuous composition measure (Keith, 2006, p. $186 \& 238)$.

Supplementary Online Materials - Table 3. Final Model for Majority Adolescents using Other Dummy-Coded Variable

\begin{tabular}{lcc}
\hline & $B(S E)$ & $B(S E)$ \\
Individual-level & $\beta$ & $\beta$ \\
\cline { 2 - 3 } & Adoption T2 & Maintenance T2 \\
\hline Adoption T1 & $0.37(0.02)^{* * *}$ & $-0.14(0.03)^{* * *}$ \\
Maintenance T1 & 0.40 & -0.12 \\
& $-0.10(0.02)^{* * *}$ & $0.30(0.03)^{* * *}$ \\
Non-vocational track & -0.12 & 0.30 \\
& -- & $-0.18(0.07)^{* *}$ \\
\hline School-level & & -0.07 \\
\hline Peer norm adoption & $0.04(0.18)$ & $-0.17(0.24)$ \\
& 0.04 & -0.15 \\
Peer norm maintenance & $-0.30(0.16)+$ & $0.32(0.20)^{*}$ \\
& -0.59 & 0.48 \\
<40\% majority $(v s .>60 \%)$ & $0.15(0.12)$ & $-0.14(0.14)$ \\
$40-60 \%$ majority $(v s . ~>60 \%)$ & 0.43 & -0.29 \\
& $0.14(0.08)^{*}$ & $-0.02(0.10)$ \\
\hline
\end{tabular}

$+p<.10, * p<.05, * * p<.01, * * * p<.001$

Note. The p-value of the $<40 \%$ dummy on adoption is .100 